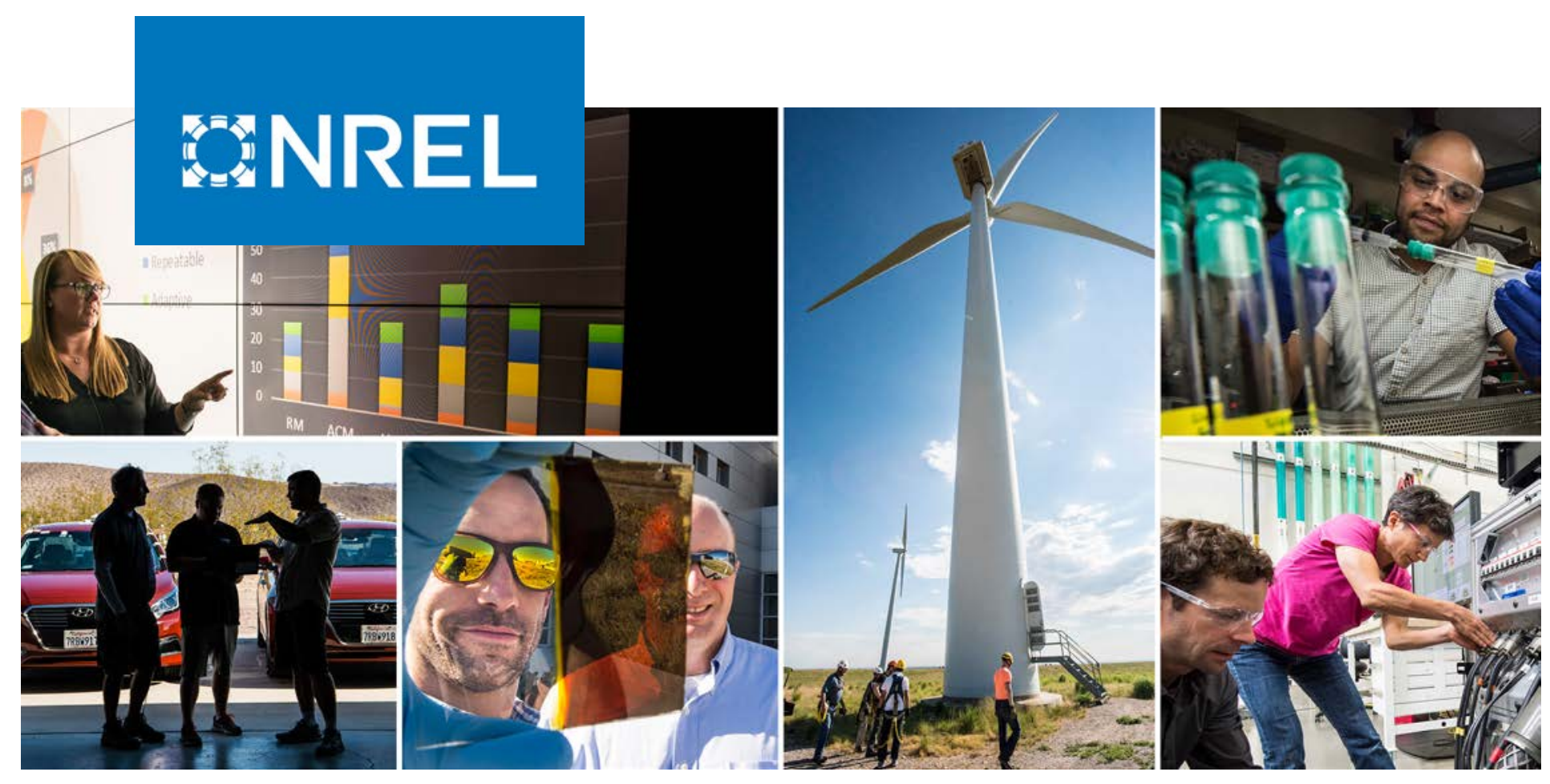

\title{
Resilience Roadmap: A Collaborative Approach to Multi-Jurisdictional Resilience Planning
}

Eliza Hotchkiss and Alex Dane

National Renewable Energy Laboratory

NREL is a national laboratory of the U.S. Department of Energy Office of Energy Efficiency \& Renewable Energy

Operated by the Alliance for Sustainable Energy, LLC

This report is available at no cost from the National Renewable Energy Laboratory (NREL) at www.nrel.gov/publications.
Technical Report

NREL/TP-6A20-73509

June 2019 


\title{
GNREL
}

\section{Resilience Roadmap: A Collaborative Approach to Multi-Jurisdictional Resilience Planning}

\author{
Eliza Hotchkiss and Alex Dane
}

National Renewable Energy Laboratory

\section{Suggested Citation}

Hotchkiss, Eliza; Dane, Alex. 2019. Resilience Roadmap: A Collaborative Approach to Multi-Jurisdictional Resilience Planning. Golden, CO. National Renewable Energy Laboratory. NREL/TP-6A20-73509. https://www.nrel.gov/docs/fy19osti/73509.pdf.

NREL is a national laboratory of the U.S. Department of Energy Office of Energy Efficiency \& Renewable Energy Operated by the Alliance for Sustainable Energy, LLC

This report is available at no cost from the National Renewable Energy Laboratory (NREL) at www.nrel.gov/publications.

Contract No. DE-AC36-08GO28308
Technical Report NREL/TP-6A20-73509 June 2019

National Renewable Energy Laboratory 15013 Denver West Parkway Golden, CO 80401 303-275-3000 • www.nrel.gov 


\section{NOTICE}

This work was authored by the National Renewable Energy Laboratory, operated by Alliance for Sustainable Energy, LLC, for the U.S. Department of Energy (DOE) under Contract No. DE-AC36-08GO28308. Funding provided by U.S. Department of Energy Office of Energy Efficiency and Renewable Energy Federal Energy Management Program Office. The views expressed herein do not necessarily represent the views of the DOE or the U.S. Government.

This report is available at no cost from the National Renewable Energy Laboratory (NREL) at www.nrel.gov/publications.

U.S. Department of Energy (DOE) reports produced after 1991 and a growing number of pre-1991 documents are available free via www.OSTI.gov.

Cover Photos by Dennis Schroeder: (clockwise, left to right) NREL 51934, NREL 45897, NREL 42160, NREL 45891, NREL 48097, NREL 46526.

NREL prints on paper that contains recycled content. 


\section{Acknowledgments}

The pilot program, in coordination with the State of Colorado, and this published Resilience Roadmap would not have been possible without the time, resources, and dedication of numerous staff members at many different organizations. The authors would like to thank a few key participants:

- Dave Adams and Marissa McInnis of the White House Council on Environmental Quality for their guidance and support

- U.S. Department of Energy staff, including Sarah Jensen and Nicolas Baker with the Federal Energy Management Program and Alice Lippert with the Office of Electricity for their programmatic support, funding and guidance, as well as Alice Madden and Tara Trujillo

- Molly Urbina, Iain Hyde, and Tanya Mann with the Colorado Resiliency and Recovery Office for their collaboration, coordination, and feedback on the road-mapping process for the State of Colorado

- Jory Maes with the State of Colorado Infrastructure Protection and Joseph O'Keefe with the U.S. Department of Homeland Security's Office of Infrastructure Protection's regional program for their involvement in workshops and reviews of content.

- Staff at the National Institute of Standards and Technology

- Other reviewers and participants who may have been inadvertently left out of the acknowledgements. 


\section{List of Acronyms}

APA

CEQ

DHS

DOE

EPA

FEMA

GIS

HUD

MOU

NASA

NIST

NOAA

NREL

PPP
American Planning Association

White House Council on Environmental Quality

U.S. Department of Homeland Security

U.S. Department of Energy

U.S. Environmental Protection Agency

Federal Emergency Management Agency

geographic information system

U.S. Department of Housing and Urban Development memorandum of understanding

National Aeronautics and Space Administration

National Institute of Standards and Technology

National Oceanic and Atmospheric Administration

National Renewable Energy Laboratory

public-private partnerships 


\section{Executive Summary}

Extreme weather and aging infrastructure are creating unprecedented challenges in the United States and around the globe. Many communities have suffered damages from a variety of severe weather-related events, including hurricanes, droughts, increasing temperatures, wildfires, and storm surges. Numerous efforts have been taken to improve resilience to protect national security, energy and water security, economic wellbeing, environmental health, and quality of life. As severe weather events increase in frequency and severity, many cities, states, tribes, and federal agencies are addressing the impacts through proactive resilience planning and measures. In an effort to support communities with resilience planning, in 2013 the White House Council on Environmental Quality (CEQ) initiated preparedness pilot projects designed to showcase community resilience planning in the City of Houston and the State of Colorado.

The National Aeronautics and Space Administration was tasked with leading the pilot for the City of Houston and the U.S. Department of Energy's (DOE's) National Renewable Energy Laboratory (NREL) was tasked with leading the pilot project for the State of Colorado.

The CEQ Colorado pilot project was a collaborative effort of numerous federal, state, and local entities that benefitted greatly from the proactive efforts of the Colorado Resiliency and Recovery Office. This Resilience Roadmap was created to document the lessons learned from the Colorado pilot project and to outline a replicable process for regional resilience planning across multiple jurisdictions. In addition to the process elements, the roadmap presents potential solutions for enhancing resilience to all hazards in energy and water infrastructure, as well as critical infrastructure and facilities. This publication is the full, technical document for the Colorado pilot project. The overarching resilience planning process used is also summarized in a user-friendly web-version on NREL's website (visit www.nrel.gov/resilience-planning-roadmap) for easier access and replicability.

NASA's pilot project with the City of Houston is summarized separately (visit https://toolkit.climate.gov/case-studies/climate-resilience to learn more). 


\section{Table of Contents}

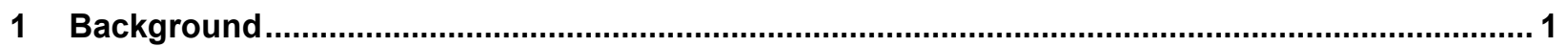

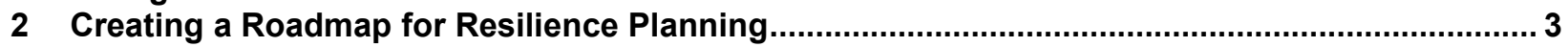

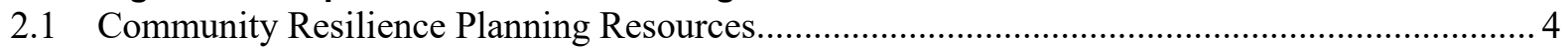

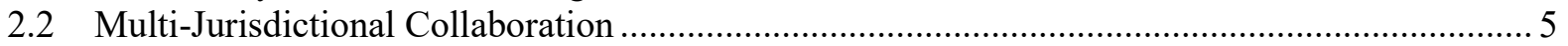

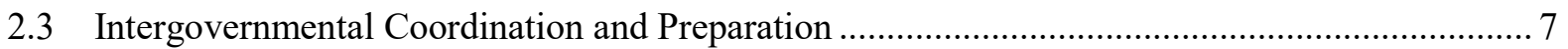

2.3.1 Intergovernmental Stakeholder Engagement ..................................................... 9

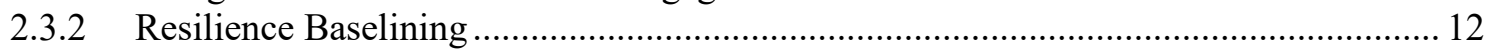

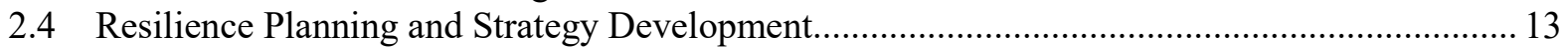

2.4.1 Shared Interdependencies, Vulnerabilities, and Performance Goals............................ 14

2.4.2 Resilience Strategy Development and Prioritization................................................. 21

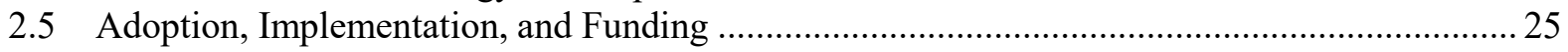

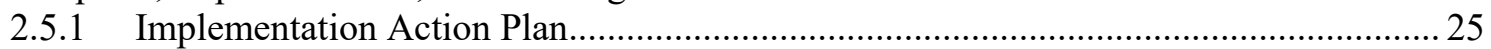

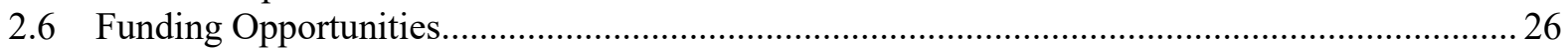

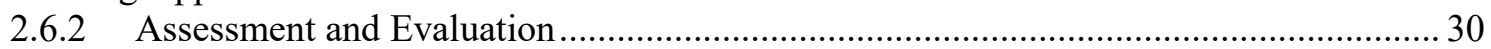

3 Conclusion

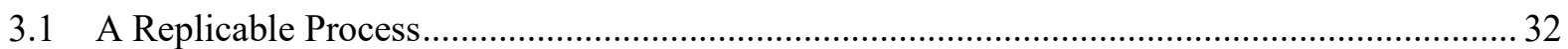

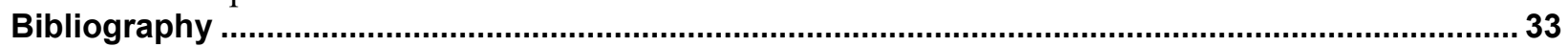

Data Sources for Information on Current Energy Use (Baseline) ...................................................... 38

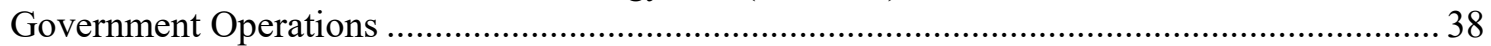

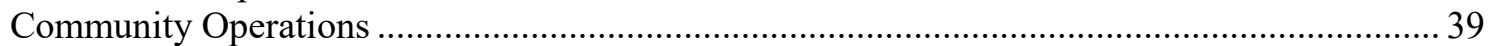

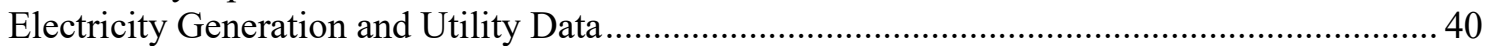

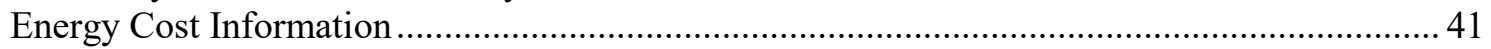

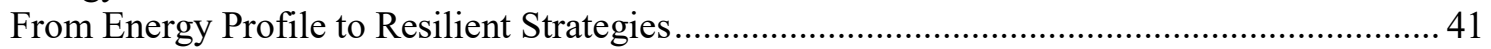

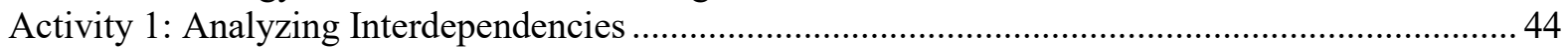

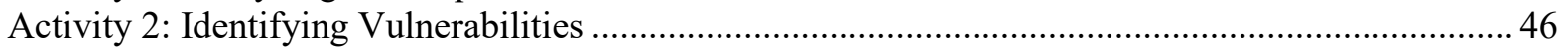

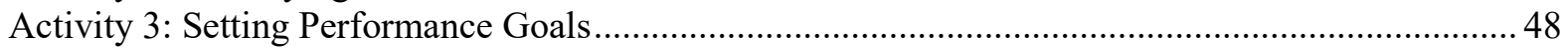

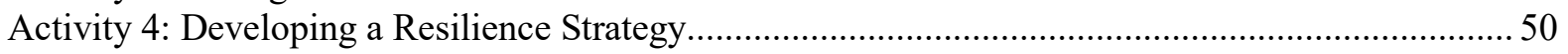

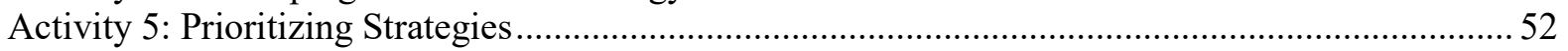




\section{List of Figures}

Figure 1. Resiliency planning cycle, starting with Intergovernmental Coordination and Preparation ......... 3 Figure 2. Preparedness pilot framework for a multi-jurisdictional and intergovernmental engagement and planning process.

Figure 3. Intergovernmental and multi-jurisdictional planning roadmap for resilient infrastructure systems

Figure 4. Intergovernmental planning process for resilient regions and infrastructure systems

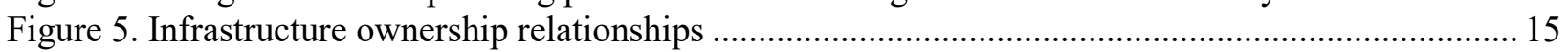

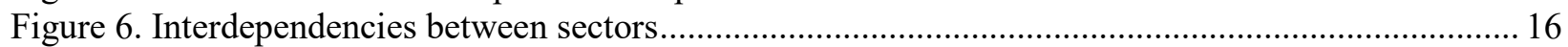

Figure 7. Example of a federal campus relying on municipal infrastructure and services for operations .. 18

Figure 8. NIST recovery time prioritization chart .......................................................................... 21

Figure 9. Example of a resilience action plan template …................................................................. 25

Figure 10. Example of a resilient/disaster recovery/green infrastructure bond model ............................. 29

Figure C-1. Estimate of city energy profile using DOE's City Energy Profile Tool................................. 41

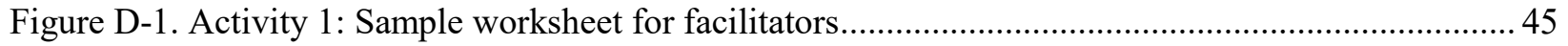

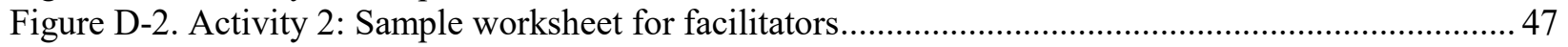

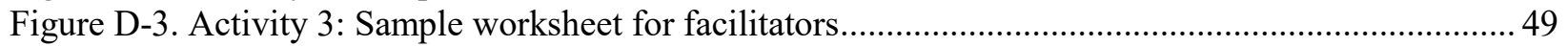

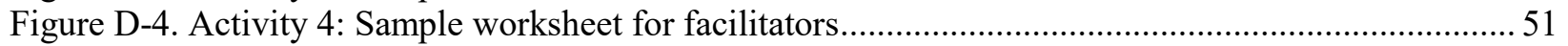

Figure D-5. Activity 5: Sample worksheet for facilitators....................................................................... 53

\section{List of Tables}

Table 1. Existing Preparedness and Resilience Planning Resources ...................................................... 4

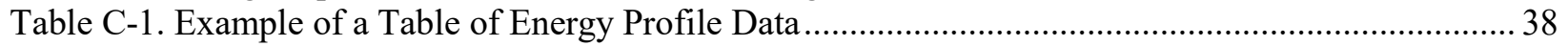

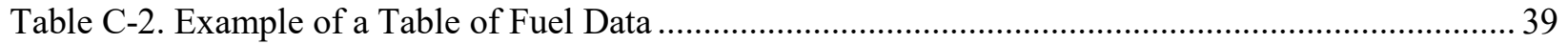

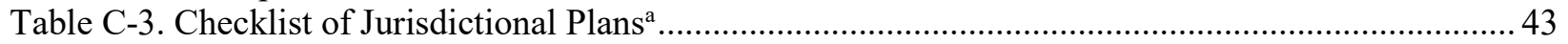




\section{Background}

According to a study by the U.S. National Aeronautics and Space Administration (NASA) and the National Oceanic and Atmospheric Administration (NOAA), surface temperatures on Earth in 2015 were the warmest since 1880 . The study reported that "globally-averaged temperatures in 2015 shattered the previous mark set in 2014 by $0.23^{\circ} \mathrm{F}\left(0.13^{\circ} \mathrm{C}\right) .{ }^{1}$ The results of these temperature increases can be seen in weather pattern changes and severe weather events. As severe weather increases in frequency and severity, many cities, states, tribes, and federal agencies are addressing the potential impacts of future threats and vulnerabilities. ${ }^{2}$ Numerous efforts have begun to improve resilience in an effort to protect national security, energy and water security, and economic and environmental well-being and maintain a high quality of life.

As part of recommendations made in 2013 by the President's State, Local, and Tribal Leaders Task Force on Preparedness and Resilience, the White House Council on Environmental Quality (CEQ) tasked the U.S. Department of Energy's (DOE's) National Renewable Energy Laboratory (NREL) with leading a preparedness pilot for the State of Colorado and NASA with leading a pilot for the City of Houston. The recommendation to commit to preparedness pilots was intended to (1) involve key federal agencies in each community and (2) bring together federal agencies and local communities to assess and plan for their region-specific vulnerabilities. The goal of the effort was to advance preparedness planning on the ground and help create models for other communities and agencies to follow. The outcomes of the two pilot projects were anticipated to be different based on the scale and threats associated with two geographically diverse locations. This document is an outcome of the Colorado pilot project only.

CEQ announced the pilots in the summer of $2014,{ }^{3}$ when the State of Colorado was in full recovery mode after recent wildfires (2012 and 2013) and floods (2013) had impacted a significant portion of the Front Range of Colorado's Rocky Mountains, which is the most populated region in the state. Because recovery efforts were underway, NREL engaged the Colorado Resiliency and Recovery Office (CRRO) in the pilot project efforts to alleviate the burden on the impacted communities, and to coordinate efforts through technical input to the state's processes. Starting in 2014, the state identified a need to integrate future-looking resilience considerations into its recovery process and in everyday business practices, and in 2015 developed the Colorado Resiliency Framework ${ }^{4}$. To fulfill priority actions identified in the Framework, the CRRO then partnered with NREL and three disaster-impacted counties to pilot a local resiliency planning process. The purposes of the pilot were to (1) support severely disaster-

\footnotetext{
1 "NASA, NOAA Analyses Reveal Record-Shattering Global Warm Temperatures in 2015," NASA, Release 16008, January 20, 2016 and updated August 6, 2017, http://www.nasa.gov/press-release/nasa-noaa-analyses-revealrecord-shattering-global-warm-temperatures-in-2015.

${ }^{2}$ National Climate Assessment "Observed Change," National Climate Assessment, U.S. Global Change Research Program, http://nca2014.globalchange.gov/report/our-changing-climate/observed-change.

3 "Fact Sheet: Taking Action to Support State, Local, and Tribal Leaders as They Prepare Communities for the Impacts of Climate Change," The White House Office of the Press Secretary, July 16, 2014. https://www.whitehouse.gov/the-press-office/2014/07/16/fact-sheet-taking-action-support-state-local-and-triballeaders-they-pre.

${ }^{4}$ Visit the Colorado Resiliency Framework at the following link: https://www.coresiliency.com/resiliencyframeworks
} 
impacted regions in developing a unified long-term vision for resilience and (2) develop an actionable roadmap for implementation.

The CRRO worked with local partners to convene a range of local, state, federal, and nongovernmental stakeholders in three participating counties, Weld, Boulder, and El Paso. NREL provided technical assistance, as well as support with facilitation and stakeholder engagement. In each planning exercise the process used two intensive workshops, or planning charrettes, that focused on evaluating existing conditions; identifying vulnerabilities from shocks and stresses; and developing a vision, goals, and potential solutions for improving resilience. An additional workshop was convened by NREL and federal partners to engage stakeholders who had not been a part of the state's process in order to identify gaps in the process and hone in on a more direct approach for cross-jurisdictional, multi-stakeholder resilience planning, with a focus on the interdependence of communities and critical infrastructure systems. The timing of the last charrette allowed the coordinators to apply some of the approaches outlined in the Community Resilience Planning Guide for Buildings and Infrastructure Systems, which had been recently published by the National Institute of Standards and Technology (NIST). ${ }^{5}$ The lessons learned from the various charrettes were used to create a process for resilience planning with multiple stakeholders, summarized in this Resilience Roadmap.

A roadmap is generally defined as a type of strategic plan that outlines goals, desired outcomes, and tasks to be performed over specified time frames. A roadmap also outlines tasks and priorities for action from the near term to the long term, and it includes metrics and milestones to track progress made toward goals. The Resilience Roadmap outlines the process for creating a strategic plan and is intended to be used by multiple stakeholders at the levels of federal, state and local government. The overarching steps within the Resilience Roadmap are to (1) prepare and coordinate, (2) develop a plan and strategy, (3) adopt, implement, and evaluate the plan.

During the preparedness pilot activities in the State of Colorado, the term resilience was used frequently to set goals for the planning process. Resilience is defined differently in various sectors and stakeholder groups; however, it is a term that is more holistic and reaches audiences more than the term "preparedness." Thus, the pilot team chose to use "resilience" as the underlying goal throughout its efforts. The Resilience Roadmap is intended to outline the process and potential technical considerations for energy and water security, provide a compilation of lessons learned over the course of a year, as well as highlight an approach to cross-jurisdictional, interagency, and multi-stakeholder engagement targeted at preparing for risks and becoming more resilient.

\footnotetext{
${ }^{5}$ NIST, Community Resilience Planning Guide (National Institute of Standards and Technology, created April 24, 2015 and updated December 10, 2018). https://www.nist.gov/topics/community-resilience/planning-guide.
} 


\section{Creating a Roadmap for Resilience Planning}

A "resilience roadmap" is a type of strategic plan that outlines goals, desired outcomes and activities to be taken over specified time frames to increase resilience within a region or a system. A roadmap should outline tasks and priorities for action and allow progress to be tracked. The steps to creating a resilience plan include intergovernmental coordination and preparation, resilience planning and strategy development and adoption, implementation and evaluation of the plan, as outlined in Figure 1. Within those steps, there are several activities, from establishing a working group, establishing desired outcomes and goals, undertaking the planning process, undertaking visioning exercises and identifying shared vulnerabilities and interdependences to developing a resilience plan; then comes implementing the plan and finally measuring impacts and adjusting the plan as needed.

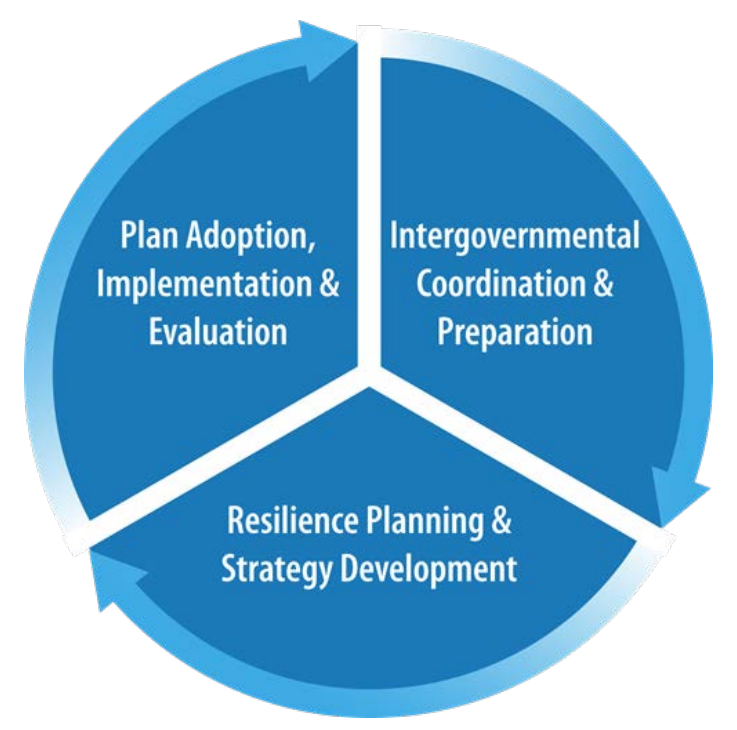

Figure 1. Resiliency planning cycle, starting with Intergovernmental Coordination \& Preparation

The planning process occupies the largest portion of the Resilience Roadmap. In planning for the future, local governments are increasingly compelled to assess threats and vulnerabilities. The process of long-term planning for these uncertainties is a core responsibility of proactive governance. Disaster incidents in recent U.S. history, including Hurricane Katrina, Super Storm Sandy, and wildfires in the western United States have propelled the urgency and awareness for this type of planning nationwide. Following these disasters and incidents, communities are often left to ask the question: Could the failure of infrastructure systems, property damage, and human impact have been prevented or minimized? To proactively address this question, federal, philanthropic, and nonprofit entities have played an instrumental role in developing resources and guidance to support communities nationwide. Such efforts are intended to increase the adaptive capacity of local governments and integrate the following themes into long-term planning:

- Intelligence about long-term vulnerabilities posed by natural hazards, system shocks, and system stresses on critical infrastructure and operations

- Strategic planning to address hazard mitigation and resilience goals into long-term plans

- Implementation of strategic plans through policies, regulations, programs, and capital improvement projects. 


\subsection{Community Resilience Planning Resources}

To support the process of addressing these long-term planning themes, several frameworks have been developed. Table 1 provides examples of resources that have been developed to support long-term planning efforts of local governments. The diverse topic areas include resilience planning, adaptation and hazard mitigation planning, post-disaster recovery planning, comprehensive planning, sustainability planning, green infrastructure, and energy reliability. Although topic areas differ, a general planning framework becomes apparent. Typically visualized in the form of a cycle, the frameworks share common procedural elements and steps, including stakeholder engagement, baseline condition definition, goal identification, strategy development, prioritization, adoption, and measurement and verification. This type of planning cycle is familiar to local government leadership and staff, as it is commonly used as a framework for comprehensive planning and participatory community engagement.

Table 1. Existing Preparedness and Resilience Planning Resources

\begin{tabular}{ll}
\hline Themes & Resources \\
\hline $\begin{array}{l}\text { Community resilience } \\
\text { planning }\end{array}$ & $\begin{array}{l}\text { Community Resilience Planning Guidebook for Buildings and } \\
\text { Infrastructure Systems }\end{array}$ \\
& $\begin{array}{l}\text { Climate Smart Resiliency Planning: A Planning Evaluation Tool for } \\
\text { New York State Communities Version 2.0 }\end{array}$ \\
\hline $\begin{array}{l}\text { Coastal adaptation } \\
\text { planning }\end{array}$ & $\begin{array}{l}\text { National Climate Assessment: Response Strategies, online resource } \\
\text { Being Prepared for Climate Change: A Workbook for Developing Risk- } \\
\text { Based Adaptation Plans }\end{array}$ \\
\hline Hazard mitigation & Hazard Mitigation: Integrating Best Practices into Planning $^{\mathrm{e}}$ \\
\hline Disaster recovery & Planning for Post-Disaster Recovery: Next Generation ${ }^{\mathrm{f}}$ \\
\hline Strategic energy planning & Guide to Community Energy Strategic Planning \\
\hline General preparedness & Department of Housing and Urban Development (HUD) Community \\
& Resilience, online resource portal \\
\hline
\end{tabular}

a "Community Resilience Planning Guide," National Institute of Standards and Technology, April 24, 2015 and updated

December 10, 2018, https://www.nist.gov/topics/community-resilience/planning-guide.

${ }^{\mathrm{b}}$ New York State Climate Smart Communities, Climate Smart Resiliency Planning: A Planning Evaluation Tool for New York State Communities Version 2.0 (New York State Climate Smart Communities, 2014) http://www.dec.ny.gov/docs/administration pdf/csrptool.pdf.

c "Downloads," National Climate Assessment, http://nca2014.globalchange.gov/downloads.

d U.S. Environmental Protection Agency, Being Prepared for Climate Change: A Workbook for Developing Risk-Based Adaptation Plans (Washington, D.C.: EPA Office of Water, 2014) https://www.epa.gov/sites/production/files/201409/documents/being prepared workbook 508.pdf.

e James C. Schwab, editor, Hazard Mitigation: Integrating Best Practices into Planning (Chicago, IL: American Planning Association, 2010) https://s3-us-gov-west-1.amazonaws.com/dam-production/uploads/20130726-1739-250454373/pas 560 final.pdf.

f James C. Schwab, Planning for Post-Disaster Recovery: Next Generation. PAS Report 576 (Chicago, IL: American Planning Association, 2014) https://www.planning.org/publications/report/9026899/.

g U.S. Department of Energy, Guide To Community Energy Strategic Planning (Washington, D.C.: U.S. Department of Energy, 2013) https://www.energy.gov/sites/prod/files/2014/05/f15/cesp guide.pdf.

h "Community Resilience," U.S. Department of Housing and Urban Development, https://www.hudexchange.info/programs/community-resilience/.

Local governments and communities committed to resilience and preparedness planning are well-served by using NIST’s Community Resilience Planning Guidebook for Buildings and 
Infrastructure Systems. ${ }^{6}$ This robust two-volume guidebook offers a framework for community resilience planning by providing topic-relevant information and activity worksheets for assessing risks, setting goals, and developing strategies for resilient infrastructure. Although this Resilience Roadmap's suggestions are similar to many of the principles in the NIST guidebook, the Resilience Roadmap seeks to provide a framework that supports cross-jurisdictional and interagency resilience planning. The road-mapping process presented here provides a broader framework for identifying shared interdependencies, vulnerabilities, and strategies addressed at a regional level, including multiple jurisdictions and various sets of intergovernmental agencies (Figure 2). It also highlights some energy and water measures, which can be implemented to enhance resilience (e.g., energy conservation can be reduce the amount of energy needed on a daily basis, as well as during a grid outage; a microgrid with onsite renewable energy could provide power to critical loads during a grid outage, if designed to do so, etc.).

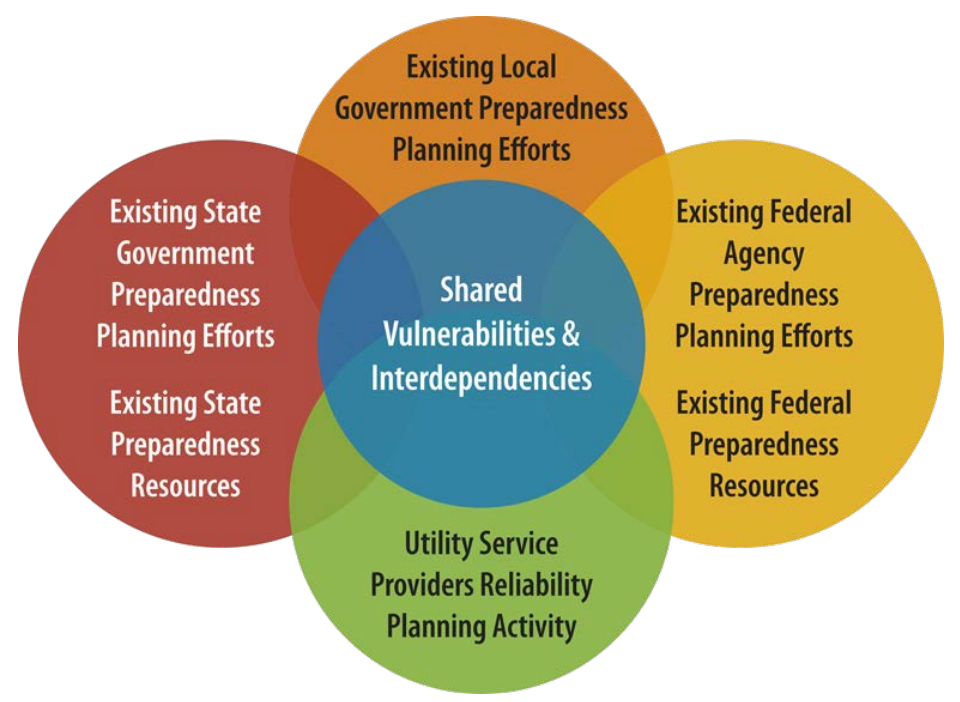

Figure 2. Preparedness pilot framework for a multi-jurisdictional and intergovernmental engagement and planning process

\subsection{Multi-Jurisdictional Collaboration}

Because infrastructure systems often span broader geographic areas, the impacts of hazards, threats, vulnerabilities, and risks are not bound by jurisdictional lines. Likewise, the decisions, policies, and practices in one community can have direct or indirect impacts on other communities. Further complexity is added when ownership and operation of these infrastructure systems and service areas are unique to each region. Planning for various hazards across multiple management entities or system operators entails a higher level of communication and collaboration to be coordinated and effective at the regional scale. Although a complex task, the process of identifying regional infrastructure interdependencies and vulnerabilities ultimately yields a more robust set of resilience strategies. Adopting a multi-jurisdictional and/or intergovernmental approach has demonstrated benefits and is supported by federal planning agencies such as the U.S. Department of Housing and Urban Development (HUD), and was required as part of Executive Order 13693, Planning for Federal Sustainability in the Next

\footnotetext{
${ }^{6}$ NIST, Community Resilience Planning Guide (National Institute of Standards and Technology, created April 24,
} 2015 and updated December 10,2018). https://www.nist.gov/topics/community-resilience/planning-guide. 
Decade. HUD notes that "what is certain is that both planning and implementation will require extensive collaboration among all interested stakeholders. Public resources alone will not adequately support the investments needed for comprehensive infrastructure improvements, adaptation and disaster resilience, and sustainable housing development, among other urgent needs. Federal policy in this area is focused on trying to foster integrated approaches that cut across traditional policy silos and facilitate partnerships."7

To foster this engagement, the Resilience Roadmap provides a strategic framework to collaborate among local, state, and federal governments, as well as non-governmental partners. As part of CEQ's preparedness pilot, the Resilience Roadmap seeks to establish a replicable process for bringing together federal agencies, state governments, and local communities to assess and plan for their regionally-specific vulnerabilities and interdependencies. The roadmap is intended to provide a tangible and useful integrated planning process between governmental structures and service providers, as illustrated in Figure 3.

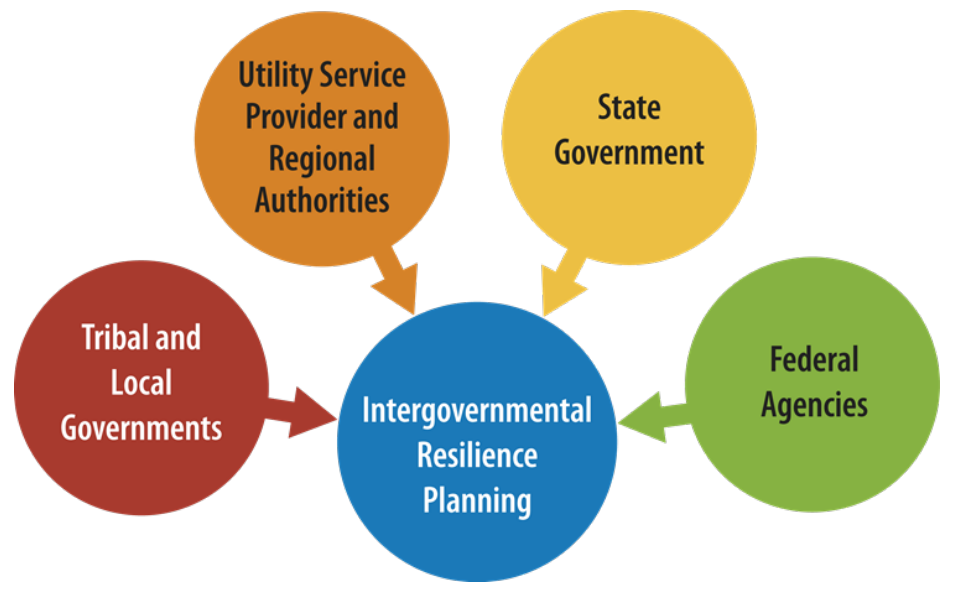

Figure 3. Intergovernmental and multi-jurisdictional planning roadmap for resilient infrastructure systems

Although each government may have resilience or preparedness planning efforts underway for their own jurisdiction, the need and opportunity still exists for intergovernmental resilience planning. Through this process, shared interdependencies and vulnerabilities are identified across jurisdictions and at a regional level. Additionally, the intergovernmental process can leverage specific agency resources which may benefit a broader set of jurisdictions participating in the regional planning effort.

The initiation of this planning process and Resilience Roadmap may come from any of the governments or entities listed in Figure 3. Local governments, tribes, utility service providers, regional planning organizations, state governments, and federal agencies are all empowered to take ownership of this process and coordinate regional roadmap activities. Ownership can be initiated by forming a working group to coordinate the process for resilience planning.

\footnotetext{
7 "Partnerships and Planning for Impact," Evidence Matters, Summer/Fall 2015, Office of Policy Development and Research, U.S. Department of Housing and Urban Development, https://www.huduser.gov/portal/periodicals/em/fall15/highlight1.html\#title
} 
Figure 4 represents two processes. First, the three logistical components of the Resilience Roadmap are 1) coordinating across jurisdictions and governments to prepare for planning exercises, 2) convening stakeholders to plan and strategize resilience, and 3) adopting, implementing and evaluating the resilience plan. This is intended to be cyclical as the process will be continuous over many years.

Second, within each logistical planning component of the Resilience Roadmap, there are several phases, including stakeholder engagement, resilience baselining, identifying shared interdependencies, vulnerabilities and performance goals, resilience strategy development and prioritization, plan adoption, implementation and funding, and finally, assessment and evaluation. Figure 4 illustrates these phases and each phase is discussed in detail in the following sections. Following these phases in order, starting with Working Group Creation and Intergovernmental Stakeholder Engagement, is important. The information, content and insights build on one another, thus leading intergovernmental planning efforts through a constructive process with tangible outputs.

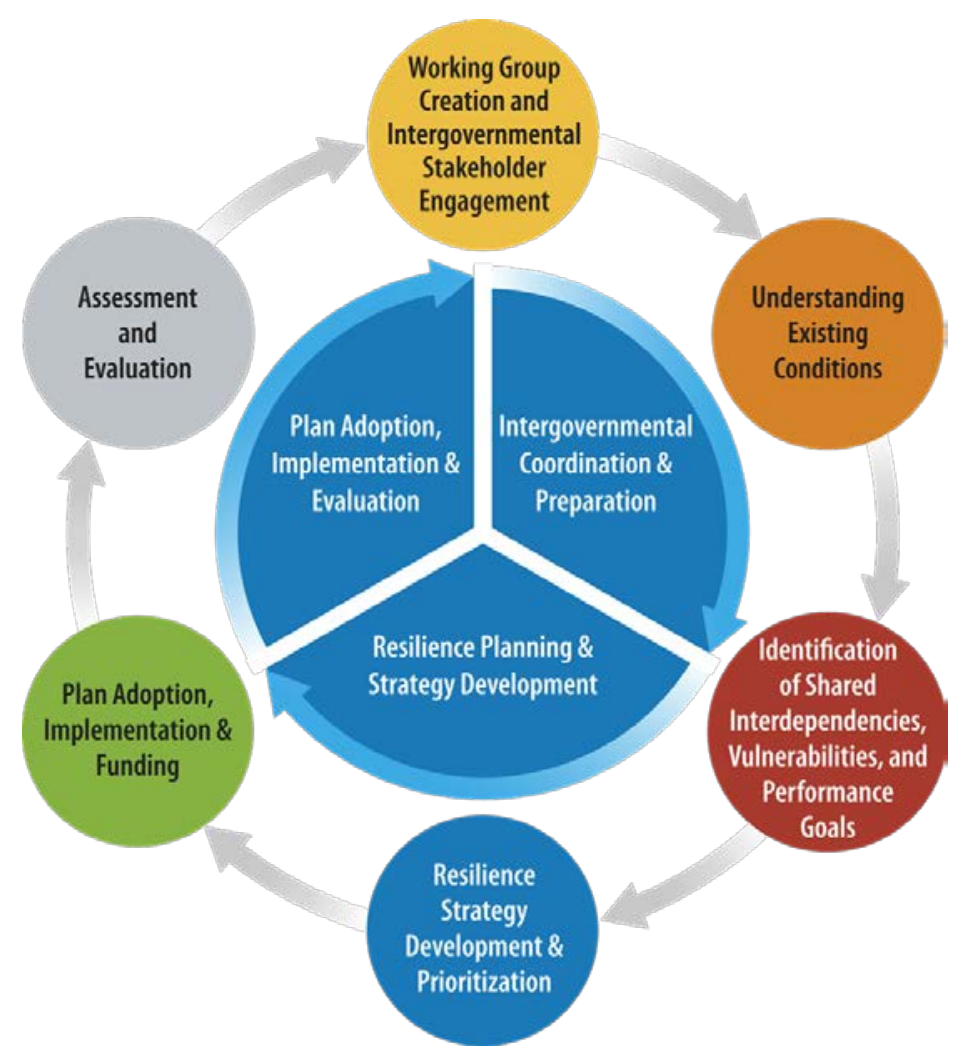

Figure 4. Intergovernmental planning process for resilient regions and infrastructure systems

\subsection{Intergovernmental Coordination and Preparation}

Intergovernmental coordination and preparation are critical first steps to resilience planning with multiple jurisdictions. Working groups are essential to the multi-stakeholder planning process. Prior to setting outcomes and goals, a planning committee will need to be formed to begin to identify or define the geographic boundaries of a resilience planning exercise, the potential multi-jurisdictional stakeholders, resilience and what it means to the stakeholder group engaged 
in the planning efforts, potential hazards and risks, as well as critical infrastructure, systems and facilities.

Establishing the geographic boundaries of a resilience planning exercise is essential to the process. The scope of the planning exercise will determine the stakeholders who need to be involved, the potential hazards, and the types of infrastructure or facilities that need to be assessed. The geographic region could include a city, a county, a federal campus and its surrounding support facilities, or be as large as an island, a tribal territory, state, or an operational region within an agency or organization (e.g., a General Service Administration region encompassing multiple states).

Identifying multi-jurisdictional stakeholders to involve in the planning process should start with a list of people and organizations providing support roles to operations within the defined geographic area. Stakeholders could include emergency personnel, planning officials, and key government agencies, just to name a few. Stakeholders who have control over policies and regulations, have access to data, or have the potential to influence decisions should be engaged in the planning process.

Resiliency should be defined with the stakeholders to determine the ultimate outcome of the plan. A list of definitions can be gathered in advance to guide the conversation. The federal sector will most likely commit to using a definition outlined in an Executive Order or another mandate, whereas a municipal government may choose to create their own definition of resilience. Understanding the definition and justification for choosing that definition at each level of government is important to goal setting exercises. NREL defines resilience as a system's ability to anticipate, prepare for, and adapt to changing conditions and withstand, respond to, and recover rapidly from disruptions through sustainable, adaptable, and holistic planning and technical solutions. A sample of resilience definitions is provided in Appendix A as a resource.

Potential hazards and threats need to be identified in order to understand the potential impacts to communities and, eventually, the potential resilience solutions to consider. Though the focus of the CEQ Colorado Pilot was intended to be on natural or technological hazards resulting from natural impacts, an all-hazards approach may be a more holistic way to incorporate the many needs of various stakeholders and utilize limited resources during resilience planning. The State of Colorado engaged communities to consider both shocks (natural and human caused) and stresses, and discussions were not limited in what communities could consider. For example, El Paso County considered wildfires, floods, and terrorism. The county did not analyze data or hazard area delineations since that is generally covered by hazard mitigation plans. An allhazards approach would account for the following:

- Natural hazards resulting from acts of nature, severe weather, changes in climate (e.g., severe winter storm, floods, earthquakes, hurricanes, and solar flares)

- Technological hazards resulting from accidents or the failures of systems and structures (e.g., bridge collapse, grid outage)

- Threats or human-caused incidents resulting from the threats or intentional actions of an adversary (e.g., cyber, acts of terror). 
Identifying critical infrastructure will assist with determining where there are interdependencies among systems, potentially within different jurisdictions, as well as prioritizing infrastructure to strategically utilize limited resources. This may be an exercise the planning committee decides to undertake, or they could utilize efforts within the federal U.S. Department of Homeland Security (DHS) or state-level Office of Homeland Protection. Critical infrastructure may be defined as buildings, roadways, waterways, or other systems (e.g., electric grid, water treatment facilities) that support life and operations of a community or organization. Each entity will have a different definition of criticality. For example, Presidential Policy Directive 21: Critical Infrastructure Security and Resilience defines different infrastructure sectors for DHS in an effort to create a national policy to strengthen and maintain secure, functioning, and resilient critical infrastructure. More information is provided in Section 2.2.1.2 (Identifying Vulnerabilities).

Another important step in the process to creating a multi-stakeholder, crossjurisdictional, interagency roadmap for resilience is establishing a set of desired outcomes and goals. This part of the process is essential to the success of any plan, but it is particularly crucial for resilience planning

Formalize multi governmental partnerships for recovery.

These partnerships can help in resource sharing and interagency communication - both horizontally among agencies and organizations and vertically among different levels of government-to break down institutional barriers and collectively solve problems. [Partnerships] can be especially useful in disasters involving multiple jurisdictions to coordinate policy and funding flows as well as foster consistency in policy development, interpretation, and negotiations with state and federal partners. -American Planning Association for various reasons. Resiliency needs to be defined and will vary depending on the stakeholders involved; interdependencies and threats and/or hazards need to be identified; and cascading effects of impacts to critical infrastructure need to be discussed in order to outline desired outcomes and goals. Each of these steps is discussed in detail in the following sections.

\subsubsection{Intergovernmental Stakeholder Engagement}

Stakeholder engagement is a critical undertaking to develop an effective and enduring plan. It can be the longest and most time-intensive step in the planning process. It is essential to identify and engage the appropriate stakeholders, including those with decision-making authority and relevant expertise.

Fostering an intergovernmental resilience planning initiative relies on the development of an inclusive multi-government approach at the regional level. A sense of which entities to engage is better understood after establishing the geographic boundary of the planning initiative. Once the boundary is established, stakeholders can be engaged to solicit their cooperation, and encourage them to share what they have already accomplished in terms of preparedness, resilience, and sustainability. Geographic boundaries may be modified during the course of stakeholder conversations, so it is important to note that this is an adaptive process. Also important to preparation is identifying what potential desired outcomes stakeholders may have as a result of regional resilience engagement and planning. Effective outcomes of multi-government partnerships have been evidenced by the American Planning Association (APA) in discussion of 
post-disaster recovery efforts, as noted in the text box. ${ }^{8}$ Due to the nature of this roadmap, the various stakeholders that may need to be engaged include federal, state, tribal and local governments.

\subsubsection{Federal Stakeholder Engagement}

Federal stakeholders take on numerous roles, but they are primarily providers of funding and/or services and an owner and operator of systems and operations within numerous communities nationwide. Government buildings often exist within urban areas or on campuses, sharing the infrastructure systems with communities and regions. With recent executive initiatives Federal buildings and operations must lead by example and serve as a model for resilience in its investments, operations, and programs. ${ }^{9}$

Federal facilities and operations should serve as models for resilience by ensuring that potential impacts are taken into account in all stages of facility planning, design, construction, and management. Current and future water, energy, and other resource demands associated with federal activities should also be evaluated and planned for in light of projected changes in demand and climate, and in cooperation with local and regional managers and community officials. This process is intended to protect the federal government's investments in its facilities and the economic benefits they provide to regions. The results would also help protect the water resources and ecological health of regions in the face of long-term stressors,

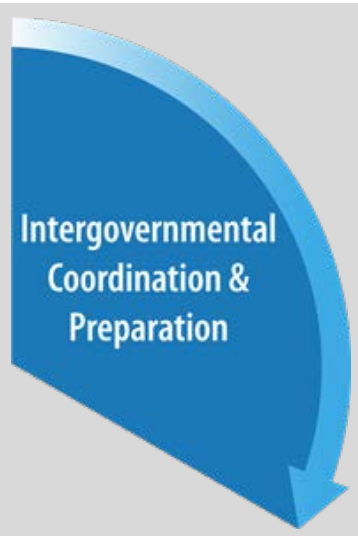

\section{Who should be included?}

\section{Federal Regional Representatives}

- Federal agency leadership

- Facility and fleet operators/managers and utility managers for federal installations/campuses/buildings

- Long range planners for federal installation/campuses/ buildings

- Emergency and response management personnel and DHS

- Federal agency representatives with geographic information system (GIS) and data expertise

- Technical experts.

\section{Tribal Representatives}

- Tribal leadership

- Tribal planners

- Active members of the tribal council

\section{State Representatives}

- Emergency planners and responders

- Homeland security officers

- Department of local affairs

- Office of disaster recovery and resilience

- State agencies with data, GIS, or planning remits

- Energy and water planning offices

- Natural resource planners.

\section{Local Representatives}

- Elected officials and policymakers

- Community development and land-use planners

- Storm-water managers

- Hazard-mitigation planners

- Natural resource planners

- Floodplain managers

- Municipal engineers

- Emergency managers

- Town administrators

${ }^{8}$ Planning for Post-Disaster Recovery: Next Generation, APA, Accessible online at: https://www.planning.org/research/postdisaster/

${ }^{9}$ See Executive Order 13693, Planning for Federal Sustainability in the Next Decade, is an example of this type of initiative www.whitehouse.gov/the-press-office/2015/03/19/executive-order-planning-federal-sustainability-nextdecade for more. 
such as drought, and promote sustainable land use planning. ${ }^{10}$

\subsubsection{State Stakeholder Engagement}

As administrators of a wide range of programs, State governments represent an important body of stakeholders to include in the resilience planning process. State governments can also play an important role in propelling resilience planning by providing resources, fulfilling an empowerment role, and/or providing technical assistance. The State of Colorado serves as a case study of leading-by-example by developing a Resilience Framework for the state. The state provides oversight and authority of natural resources management, transportation planning, and community development services. In addition, it acts as a grants manager and provides expertise to advise local communities in planning efforts and applying for project funding. States provide functions related to hazards identification within areas of water quality, river systems, floodplain management, legal status of streams, public access, management of open space, parks, wetlands, sensitive environmental areas, infrastructure planning - especially state department of transportation, and mapping of geologic hazards (e.g. landslides, earthquakes, subsidence, etc.). Additionally, special aspects of these functions relating to pre- and post-disaster planning include inventories of critical facilities and systems, preparedness programs, grants administration for the Federal Emergency Management Agency (FEMA) hazard mitigation funds and HUD Community Development Block Grants, and grants administration for FEMA post-disaster recovery funds. States are often the repositories of system data on both natural resources and infrastructure, such as roads, bridges, lakes, and reservoirs. ${ }^{11}$

\subsubsection{Local Government Stakeholder Engagement}

Local engagement is key to developing a resilience plan. To prepare and plan a resilient infrastructure system, a multi-jurisdictional approach is necessary and beneficial. As the APA notes in Planning for Post-Disaster Recovery, "community resilience depends in part on the strength and quality of the lifelines between the community and its leadership and potential sources of assistance both within and beyond the community's borders. Much of a community's recovery after a disaster relies on the strength of the relationships its officials have built with officials in those state agencies that will be responsible for assisting with recovery. The midst of a crisis is the worst possible time to begin nurturing such relationships". ${ }^{12}$ One of the benefits of inter-governmental planning is to build relationships well in advance of an emergency situation. Local governments often coordinate the community resilience activities due to their responsibilities as an implementer of building codes, statutes, community plans, and overarching collaborator with public, non-profit and private entities.

To fully institutionalize resilience, a community would ideally have a resilience office with a chief resilience officer to provide consistency in guiding strategic visions and plans and in coordinating with leadership and community staff across departments and disciplines. Each

\footnotetext{
${ }^{10}$ State, Local, and Tribal Leaders Task Force On Preparedness and Resilience. Information and website available at https://obamawhitehouse.archives.gov/administration/eop/ceq/initiatives/resilience/taskforce

${ }^{11}$ Planning for Post-Disaster Recovery: Next Generation, APA, Accessible online at: https://www.planning.org/research/postdisaster/

${ }_{12}$ Planning for Post-Disaster Recovery: Next Generation, APA, Accessible online at: https://www.planning.org/research/postdisaster/
} 
community will need to choose the best approach for integrating resilience based on capacity and resources. In all communities it is essential to have leadership and community buy-in and engagement. $^{13}$

\subsubsection{Broadening Engagement}

Beyond government officials, it may be necessary to engage private and public stakeholders, such as regional planning organizations or utility service providers. Often, the

Major disasters rarely affect just one provider of basic utility services, such as water and energy, is not the local government. The utility service provider can take the shape of a rural cooperative (co-op) or investorowned utility. It is critical to involve representatives from the utility provider early in the resilience planning process. Often the viability of a potential strategy falls under their purview and approval process. An example is integrating distributed and backup energy systems and strategies into a

jurisdiction, especially in metropolitan

regions, so pre-existing regional governance structures can be helpful in encouraging communication, cooperation, and even collaboration in recovery planning and implementation.

-- American Planning Association grid system for resilience. See Appendix B for resources on intergovernmental stakeholder engagement.

\subsubsection{Resilience Baselining}

The planning process is most effective when all jurisdictions involved in the scope of the resilience planning process gather existing information about community operations, policies, and existing conditions before in-person, facilitated planning workshops or activities. Without the right information or understanding of existing conditions, the planning process can stall due to a lack of actionable data. Before initiating in-depth collaboration, agencies and government stakeholders should gather and document data related to emergency plans, existing community plans, ordinances and codes, maps and data on locations of critical infrastructure systems or facilities, socio-economic data that identifies areas of social vulnerability, community utility needs (e.g., energy, water and fuel use and generation), and a completed preparedness evaluation for the community, if one exists. Some examples of how this information could be used to formulate analyses and identify vulnerabilities are given below.

Stakeholders should gather geographic data related to critical infrastructure systems or facilities that provide daily operations, serve the community as a whole, or provide critical services. Desirable information on critical infrastructure could include data for, or locations of, electric transmission lines, substations and distribution networks, natural gas lines and distribution networks, critical community and emergency operations facilities, water and wastewater treatment facilities, healthcare facilities, ownership of and responsibility for operation of critical infrastructure, water distribution networks and pumping stations, stormwater collection network and treatment/outflow, fueling station networks, fuel types and emergency evacuation routes, cellular towers, service providers and fiber networks, public transportation networks, lowincome and elderly housing, emergency shelters, schools, and vulnerable populations. Community or government entities will have different priorities depending on their operational

\footnotetext{
${ }^{13}$ Community Resilience Planning Guide for Buildings and Infrastructure Systems, Volume II. National Institute of Standards and Technology Special Publication 1190 (2015). Accessible at www.nist.gov/el/resilience/upload/NIST$\underline{\text { SP-1190v2.pdf }}$
} 
needs and critical activities, so data about these should be collected with input from stakeholders. Some information may be considered sensitive, so access to data or sharing of information may be limited. Understanding where evacuation priorities exist or where energy should be focused due to infrastructure needs will help formulate resilience strategies.

Energy represents a prime example of interdependency between jurisdictions. The ability of a community or federal installation to operate and provide critical services and operations is a direct result of maintaining power during a system failure. Completing an energy profile for critical operations or a community is essential for developing resilient infrastructure strategies. Beyond documenting energy consumption patterns and generation assets, there are benefits associated with documenting existing utility service provider agreements and long-term regional forecasts for meeting needs in changes to population, demographics, and the economy, for example. One of the most important parts of the energy profile is a clear assessment of what kind of energy is used and how it is used within the jurisdiction. Gathering and evaluating this information also provides a baseline for measuring future progress toward energy reliability. More information is provided in Appendix $\mathrm{C}$ as an example of conducting an energy profile and identifying resilient solutions.

\subsection{Resilience Planning and Strategy Development}

The development of a resilience strategy requires building on the baselining activities outlined above and is best-suited for in-person, facilitated stakeholder workshops. Unlike initial stakeholder engagement, which can be completed via phone calls or emails, and the resilience baselining completed in advance, the process for intergovernmental and multi-jurisdictional planning is best completed through a series of interactive workshop activities.

An intergovernmental resilience and preparedness planning workshop can take place over one day or multiple days, depending on the ability of stakeholders to attend multiple workshops. The more complex and broader the geographic scope of the planning effort, the more time should be dedicated to the workshop and discussion, or a series of workshops can be held. The workshop format creates a forum for the in-person dialogue needed to move the regional planning effort through development of a resilience roadmap. 
Successful outcomes of the workshops include:

- An established interjurisdictional understanding of shared infrastructure interdependencies, shared vulnerabilities, and operational performance goals

- A developed set of resilience strategies (policies, programs, and projects) that are responsive to shared vulnerabilities

- Addressing of interjurisdictional and regional interdependencies and progress toward achieving the performance goals of multiple stakeholders

- Identification of next steps and commitments related to adoption of the resilience plan and strategies at jurisdictional and regional levels

- Integration of strategies into existing jurisdictional plans, policies, programs and projects

- Identification of funding and financing opportunities for implementation of the plan

- Establishment of resilience assessment, measurement protocol and/or performance indicators.

During the workshop(s), a facilitator or facilitators may guide stakeholder participation and discussion through tabletop exercises. For the roadmap, the guided discussions can be considered sequential workshop activities, and each can play a role in moving the stakeholders through the resilience planning process. A series of workshop activities has been outlined in the following section, and worksheets are provided in Appendix D to guide discussions.

\subsubsection{Shared Interdependencies, Vulnerabilities, and Performance Goals}

For regional resilience planning, shared interdependencies are considered to be shared infrastructure systems that serve the critical operations and functional performance of multiple jurisdictions. The definition of infrastructure varies widely by organization and can include structures and facilities (e.g., wastewater treatment plants or dams) and services provided by a broader array of community assets (e.g., telecommunications networks). To address preparedness, DHS defines critical infrastructure broadly as, "the assets, systems, and networks, whether physical or virtual, so vital to the United States that their incapacitation or destruction would have a debilitating effect on security, national economic security, public health or safety, or any combination thereof." DHS also mandates that critical infrastructure be "secure and able to withstand and rapidly recover from all hazards. Proactive and coordinated efforts are necessary to strengthen and maintain secure, functioning, and resilient critical infrastructure."14 DHS categorizes critical infrastructure into 16 separate sectors, including chemical, commercial facilities, communications, critical manufacturing, dams, defense industrial base, emergency services, energy, financial services, food and agriculture, government facilities, healthcare and public health, information technology, nuclear reactors, materials, waste, transportation systems, and water and wastewater systems. ${ }^{15}$ Framing the conversation of interdependencies by critical

\footnotetext{
14 “Infrastructure Security,” U.S. Department of Homeland Security, Last updated November 20, 2018. https://www.dhs.gov/topic/critical-infrastructure-security

15 "Presidential Policy Directive 21: Critical Infrastructure Security and Resilience," Presidential Policy Directive/PPD-21. (The White House Office of the Press Secretary, February 12, 2013). https://obamawhitehouse.archives.gov/the-press-office/2013/02/12/presidential-policy-directive-criticalinfrastructure-security-and-resil.
} 
infrastructure sector may help intergovernmental entities understand the drivers and mission activities within a community, as well as potential resilience strategies within each sector.

\subsubsection{Identifying Interdependencies}

The first step in framing the conversation of interdependencies is identifying the system interdependencies between the stakeholders. Critical infrastructure systems are rarely bound and internal to only one jurisdiction. Utility authorities often stretch across jurisdictional lines and serve the operations of multiple levels of government. The APA's Planning for Post-Disaster Recovery guidebook accurately captures the essence of interdependencies when it notes:

There are many agencies, private companies, and jurisdictions involved in providing transportation, infrastructure, public facilities, and utility services to a community. Many of the systems are interdependent on others; for instance, water treatment and distribution require a functioning power system. There are several types of interdependencies: physical linkages, such as the multitude of systems reliant on electric power; cyber linkages (e.g., computerized system controls that rely on telecommunications); geographic linkages (e.g., pipelines located on transportation bridges); and economic and market linkages. ${ }^{16}$

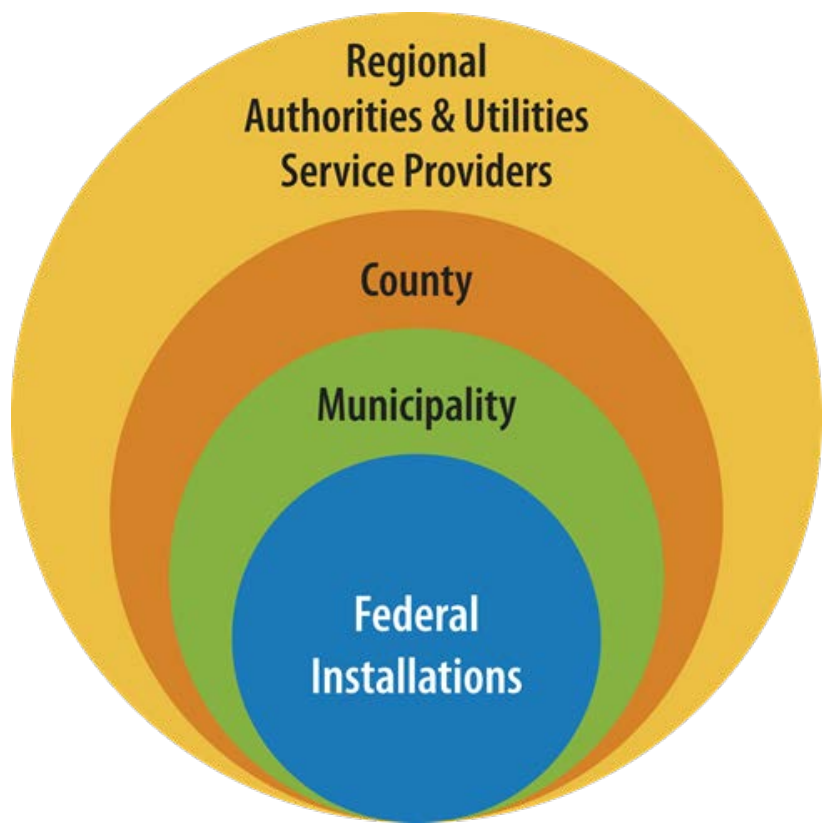

Figure 5. Infrastructure ownership relationships

With intergovernmental resilience planning efforts, it is important to untangle the complex nature of critical infrastructure systems and ownership. Figure 5 illustrates the fact that federal installations may operate in their own sphere, but often rely on infrastructure that is owned and maintained by other entities. In doing so, stakeholders can conceptualize how "upstream" impacts to critical infrastructure systems directly affect the viability and performance of their

16 James C. Schwab, Planning for Post-Disaster Recovery: Next Generation, PAS Report 576 (Chicago, IL: American Planning Association, 2014) https://www.planning.org/publications/report/9026899/. 
own abilities to maintain performance and operations. A graphic from NISTs' Community Resilience Planning Guide for Buildings and Infrastructure Systems helps conceptualize the relationships of various sectors (Figure 6). Solid lines that connect nodes within each service, as indicated by the lined boxes, represent internal dependencies. Dashed lines represent external dependencies between emergency services and supporting infrastructure systems. For instance, delivery of ambulance, fire, and police services all depend on telecommunications and roads, and energy impacts all the other sectors.

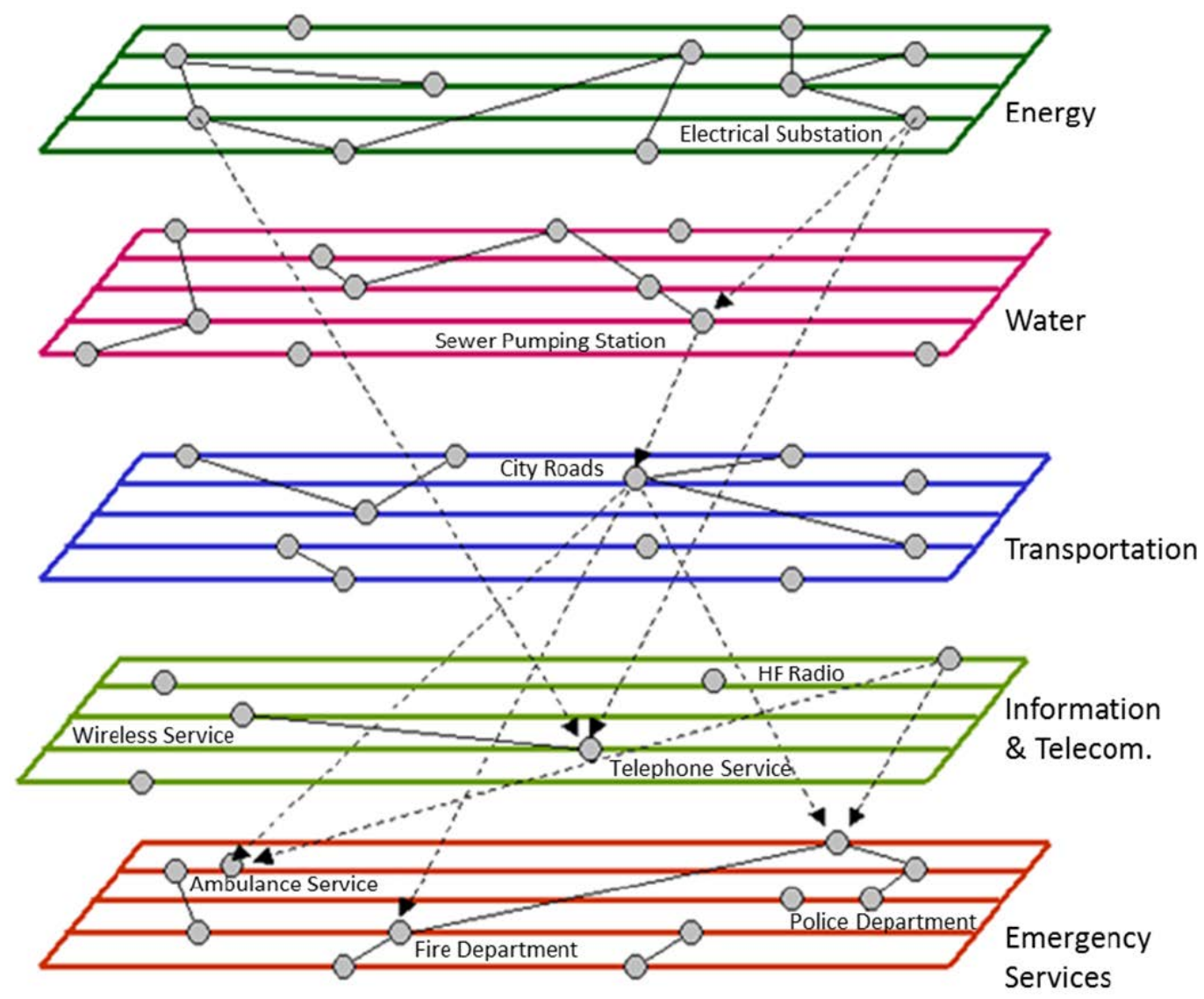

Figure 6. Interdependencies between sectors

Source: National Institute of Standards and Technology, Community Resilience Planning Guide for Buildings and Infrastructure Systems: Volume II, NIST Special Publication 1190. Figure 11-1 (pg. 41),

http://www.nist.gov/el/resilience/upload/NIST-SP-1190v2.pdf. Reprinted courtesy of National Institute of Standards and Technology, U.S. Department of Commerce. Not copyrightable in the United States.

Figure 7 is another conceptual tool for mapping infrastructure interdependencies using geographic information systems (GIS) as a foundation. The inflow and outflow of critical infrastructure systems are represented by various lines. Both Figure 6 and 7 illustrate how 
systems cross jurisdictional boundaries and provide critical services for operation of different

government functions. As an example, water

In the Colorado floods of 2013, Estes Park's road

treatment, water delivery, and wastewater pumping services may be owned and operated by the city or a unique water district operating within the city boundaries. Dependencies and interdependencies system was interrupted, limiting transportation and ultimately resulting in doctors having to be helicoptered in and out of the hospital. exist not only between the water-reliant federal operations and municipal water system, but there is also a relationship between the water systems and their need for power to treat water and pump water. Another example is the relationship between fuel delivery and transportation. Interdependencies exist between fuel delivery and providing critical transportation during emergency responses. The relationship of road access, fuel delivery, and viability of emergency services is important to consider within resilience efforts.

Workshop Activity 1 (Appendix D) is intended to guide discussions about identifying interdependencies. 


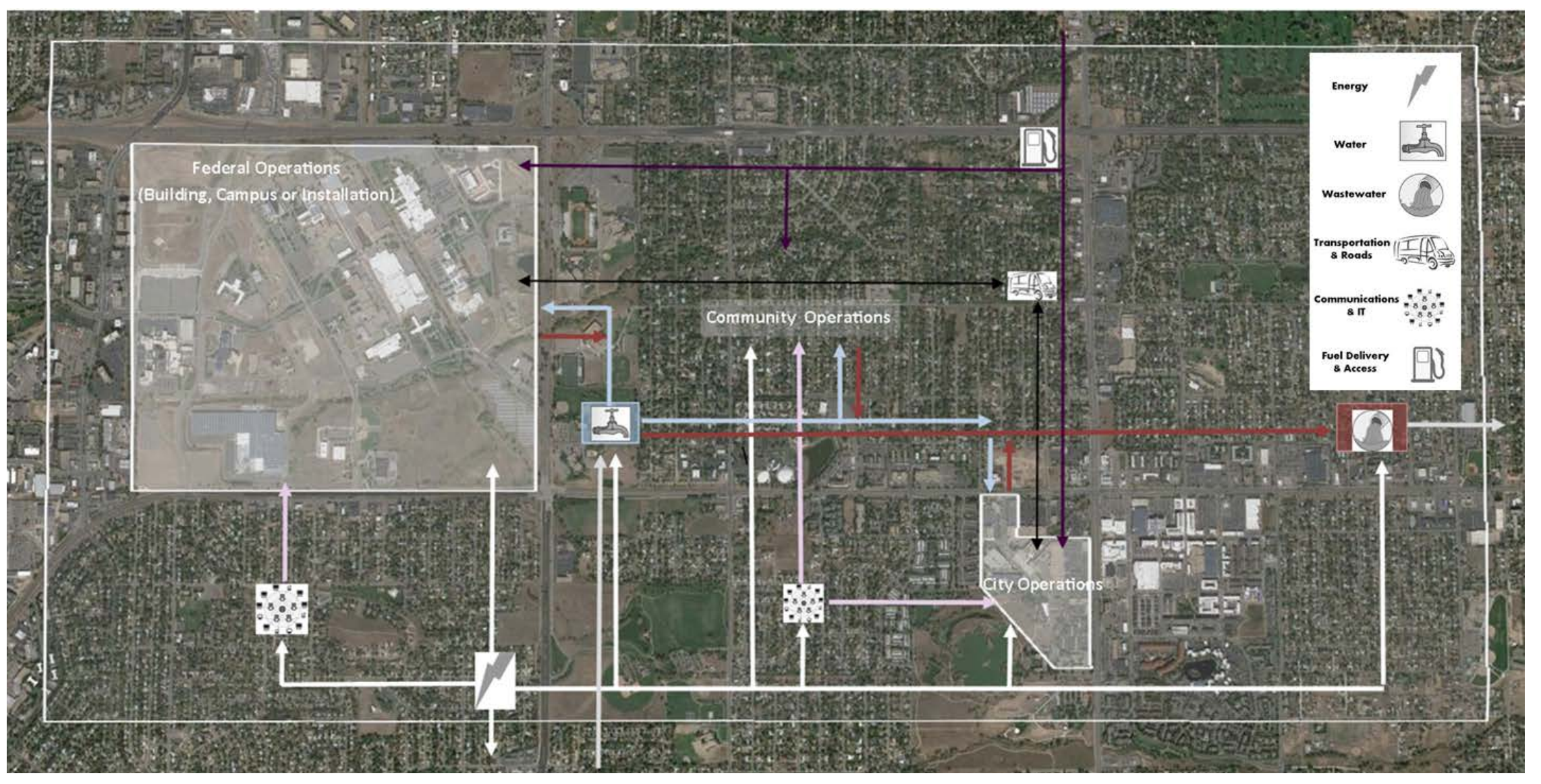

Figure 7. Example of a federal campus relying on municipal infrastructure and services for operations 


\subsubsection{Identifying Hazards and Vulnerabilities}

Risk is an important component of resilience planning. Understanding the individual characteristics of risk - threats/hazards, vulnerabilities, and consequences - will aid in understanding solutions that will reduce risk and enhance resilience. Exploring risk among multiple stakeholders is augmented by the work completed by jurisdictions and governmental entities through the baselining exercises. The outcome of those activities provides a foundation for understanding each jurisdiction's vulnerabilities, shocks, stressors, natural hazards, technological hazards, threats, or human-caused incidents. Hazards are categorized by FEMA into three major sectors, as shown below:

- Natural Hazards - Result from acts of nature, severe weather, changes in climate (e.g., severe winter storm, floods, earthquakes, hurricanes, and solar flares)

- Technological Hazards - Result from accidents or the failures of systems and structures (e.g., bridge collapse and grid outage)

- Human-Caused Incidents - Result from the threats or intentional actions of an adversary (e.g., cyber, acts of terror).

Vulnerabilities are areas within a system or process that, if exposed during a hazard or threat, could have consequences to a community, economic stability, ecosystems functionality, and so on. Vulnerabilities to hazards may be exacerbated or magnified by longer-term system stresses posed by conditions such as intense heat, drought, population change, and changing economic conditions. However, the Resilience Roadmap focuses on the short- and long-term hazards and their impacts on infrastructure vulnerability.

Workshop Activity 1 (Appendix D) is intended to guide discussions about identifying interdependencies and Activity 2 (Appendix D) is designed to guide discussions about identifying vulnerabilities during the risk assessment and resilience planning process.

\subsubsection{Setting Performance Goals}

Participating jurisdictions and governmental entities are responsible for performing core operations and functions. To ensure viability of these operations, identifying the infrastructure systems needed to maintain operations is essential. Performance goals development is the process of:

- Identifying infrastructure systems that are shared across jurisdictional lines and critical to operations of multiple governments - establishing shared goals across boundaries is important.

- Identifying the length of time it takes for those infrastructure systems to recover and regain operation, given likely hazards and/or system shock events and the sequencing needed to restore functionality (e.g., sewer, then water, and then gas). 
- Using the concepts of "where we are now" and "where we want to be" to understand current critical operations, their recovery time, and identify aspirational performance goals for critical operations viability.

- Identifying accelerated targets for shared infrastructure recovery and the viability of critical government operations.

Performance goals may be very entityspecific, but they are important to discuss, as different stakeholders may have similar goals. NIST's Community Resilience

During the Colorado floods of 2013, the interdependencies between the energy sector, water treatment facilities and critical facilities, such as hospitals became evident when power was disrupted to water treatment facilities, thus impacting the potable water supply available at hospitals. Reliable power and clean water are essential to a hospital's ability to care for patients. Planning Guide ${ }^{17}$ describes this process and serves as a good model for setting long-term resilience goals to guide resilience planning, prioritization of activities, and development of implementation strategies. One example provided in the guide is that a community may prioritize its infrastructure improvements to attract new business and enhance economic resilience. Redeveloping a flood plain to become a community park, for example, could be prioritized to mitigate flooding and protect infrastructure while using natural processes. Long-term goals will help guide the decision-making process around resilience activities. Aligning goals with community development plans and institutionalizing resilience will help achieve those goals.

Stakeholders may benefit from using the NIST recovery time framework to determine their priorities for critical infrastructure. The chart in Figure 8 establishes a common language for looking at the baseline conditions and where the stakeholders would like to be. These discussions also help guide the types of resilience solutions that should be considered. For example, a hospital that cannot lose power and needs clean water to operate may choose to install renewable energy backup systems with islanding control to isolate the energy system from the grid so that it can operate during power outages. That same hospital may discuss resilience strategies, such as gravity fed system design, with the water and wastewater treatment facilities from which it receives services. The connection between goals and solutions becomes more evident as the resilience plan is developed, which is discussed in the next section. Appendix D provides suggested conversation topics and tools for establishing shared performance goals.

\footnotetext{
17 “Community Resilience Planning Guide,” National Institute of Standards and Technology, created April 24, 2015 and updated December 10, 2018, https://www.nist.gov/topics/communityresilience/planning-guide.
} 


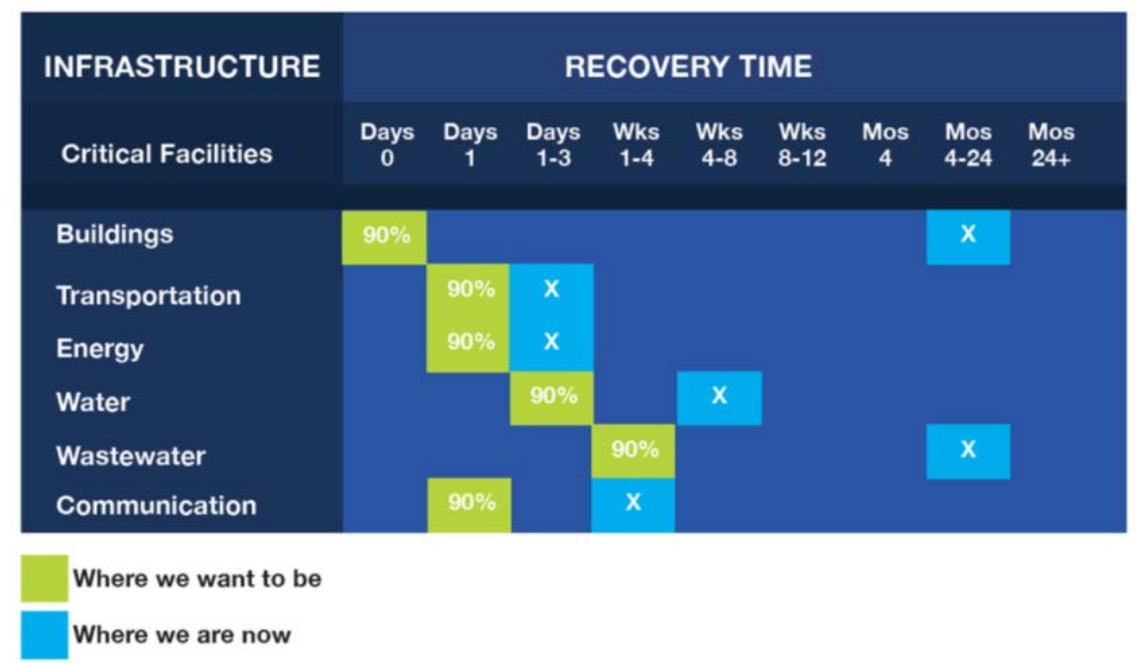

Figure 5. NIST recovery time prioritization chart

Source: National Institute of Standards and Technology, Community Resilience Planning Guide for Buildings and Infrastructure Systems: Volume II, NIST Special Publication 1190. Figure 11-1 (pg. 41),

http://www.nist.gov/el/resilience/upload/NIST-SP-1190v2.pdf. Reprinted courtesy of National Institute of

Standards and Technology, U.S. Department of Commerce. Not copyrightable in the United States.

\subsubsection{Resilience Strategy Development and Prioritization}

Based on activities in the coordination and preparation phase, a strategy can be developed. The steps that have been utilized for developing strategies and prioritizing solutions or actions include:

1. Making the case for regional strategy development

2. Discussing common criteria for resilient solutions/systems (e.g., avoidance, diversity, redundancy, etc.)

3. Discussing categories of approaches for organizing specific resilience solutions

a. By action type (planning, policy, program, investment)

b. By jurisdictional scale (fed, state, local)

These steps will naturally involve discussing approaches for prioritizing solutions and the overarching strategy based on common or shared goals across stakeholders.

There are many considerations for developing resilience strategies. Communities are shaped by their natural and engineered environments, and many factors influence longterm resilience. Determining what those drivers may be, where there are existing plans that support resilience, and where opportunities exist to improve resilience will be important when establishing a strategy and prioritizing solutions. Common characteristics used to establish resilient systems include: ${ }^{18}$

\footnotetext{
${ }_{18}$ Jamais Cascio, “The Next Big Thing: Resilience.” Foreign Policy (September 28, 2009). Cascio's work has been cited by both the Government Finance Officers Association and the International City/County Management Association (ICMA), https://www.planning.org/pas/reports/pdf/PAS 576.pdf.
} 
- Avoidance: This means either taking proactive or implementing reactive measures to reduce the likelihood or impact of threats on a system.

- Diversity: Avoid a single point of failure or reliance on a single solution.

- Redundancy: the inclusion of extra components in case of system failure (e.g., backup generators, spare parts for equipment, two electricity lines feeding a site or building).

- Decentralization: For energy systems this means introducing a greater number of small-capacity units that are all connected to the larger energy network or grid to generate energy at a local level, often utilizing onsite renewable energy technologies. Transparency: Effective communication of problems or challenges. Transparency makes it easier to determine where a problem may lie; therefore, sharing plans and preparations lets others help find potential gaps in resilience.

- Collaboration: the process of working together to produce or create something effective or useful. In the resilience space, collaboration can help with sharing resources and incorporating creative solutions.

- Failing gracefully: When a failure occurs, the system goal is for a failure state that will not make things worse.

- Flexibility: By not anticipating stability, an organization can be ready to change when the system is not working.

- Foresight: Foresight involves anticipating change, monitoring conditions to account for change when it occurs, analyzing trends, and identifying emerging vulnerabilities.

These characteristics help define the nature of resilience solutions. In generating and prioritizing resilience strategies, specific solutions can be organized in a number of ways, including by type of action (e.g., planning, policies, programs, and capital investment) or by level of jurisdictional authority (e.g., federal, state, or local level). Specific implementation strategies can be diverse because they can range from specific projects, such as seawall hardening, to broader policy adoption of more resilient and energy efficient building codes and/or land acquisition programs to protect infrastructure from future flooding hazards. To understand this landscape, it is helpful to consider resilience strategies falling into four overarching types of actions. These actions are shown below with examples for illustration:

- Long-term planning: Efforts to guide future development and growth to align with community goals. Long-term planning efforts can take the form of comprehensive community plans risk assessments, hazard mitigation plans, watershed plans, and others.

- Regulations and policies: Policies are typically rules that are made by organizations to achieve specific goals. A regulation has the effect of a law and is considered as a restriction that is imposed by authorities. Examples include zoning, subdivision regulations, flood plain regulations, and building codes.

- Programs: Long-term structured initiatives, like capacity building initiatives, land acquisition, low-income housing programs, are developed by an organization to implement projects to achieve goals. 
- Capital projects: These include capital improvement projects, decentralized backup energy generation for critical facilities, passive storm-water management system designs, and others which help maintain or improve an asset or infrastructure. Capital projects are usually funded out of an annual budget and are typically new construction, renovations, or replacement projects.

Additionally, jurisdictional scales represent another set of categories into which resilience strategies may be organized, including strategies at the federal, state, and local levels.

Potential resilience strategies are well-documented and can be accessed through the following resources at the federal and local levels:

- Rosina Bierbaum, Arthur Lee, Joel Smith, Maria Blair, Lynne M. Carter, F. Stuart Chapin III, Paul Fleming, et al. Chapter 28: Adaptation. In Climate Change Impacts in the United States: The Third National Climate Assessment (U.S. Global Change Research Program: 2014). doi:10.7930/J07H1GGT. https://nca2014.globalchange.gov/report/response-strategies/adaptation.

- Recommendations made by President Obama's State, Local, and Tribal Leaders Task Force on Climate Preparedness and Resilience in Fact Sheet: Taking Action to Support State, Local, and Tribal Leaders as They Prepare Communities for the Impacts of Climate Change," The White House Office of the Press Secretary, July 16, 2014, https://www.whitehouse.gov/the-press-office/2014/07/16/fact-sheettaking-action-support-state-local-and-tribal-leaders-they-pre.

- James C. Schwab. Planning for Post-Disaster Recovery: Next Generation. Planning Advisory Service Report 576 (Chicago, IL: American Planning Association, 2014) https://www.planning.org/publications/report/9026899/.

- "Community Resilience Planning Guide," NIST, April 24, 2015 and updated December 10, 2018, https://www.nist.gov/topics/community-resilience/planningguide.

Implementing a plan is the only way resilience can be enhanced. When developing a regional, intergovernmental resilience strategy it is important to keep in mind that jurisdictional activity drives resilience forward. Many of the existing solutions are able to only be implemented by a singular jurisdiction, exercising their own statutory authority. Similarly, traditional funding and public financing is often tied to one governmental entity. However, the argument for regional and intergovernmental resilience planning and strategy implementation is strong.

Federal funding options for resilience planning and implementing is growing. Expanding levels of research and analysis are in support of regional exchange and intergovernmental action. ${ }^{19}$ The Resilience Roadmap seeks to draw out the co-benefits of planning and implementing strategies for shared infrastructure systems. Considering the benefit of data and information exchange between jurisdictions and other governmental entities may prove helpful. The broader regional context may prove effective in efforts to develop a

${ }^{19}$ HUD, Evidence Matters (Summer/Fall 2015). https://www.huduser.gov/portal/sites/default/files/pdf/EMNewsletter-summer-fall-2015.pdf. 
richer information exchange from which to make decisions. It may be necessary for agreements and protocols to be established to further resilience planning. Tools to consider include:

- Entering into intergovernmental agreements or memorandums of understanding (MOUs) for data exchanges

- Developing protocols for exchanging, storing, and maintaining infrastructure system data

- Creating new opportunities for resilience strategy development through regional planning organizations and metropolitan planning organizations

- Developing agreements between state and local governments to clarify roles and where the state may support local governments (e.g., data aggregation, analysis, and mapping)

- Expanding the potential for federal, state, or regional planning organizations to serve as knowledge providers and technical experts for new and innovative resilience strategies and approaches.

Workshop Activity 4 (Appendix D) is intended to guide discussions about developing a resilience strategy.

The last step in the workshop process is prioritizing the strategies developed. By doing so, participating jurisdictions and governmental entities can lay the groundwork for future collaboration on targeted planning, policy, programs, and projects. Individual governments and jurisdictions may be able to move forward with some strategies that are within their statutory and financing authority; other strategies will rely on regional collaboration either horizontally across jurisdictions or vertically among local, state, and federal agencies.

It is suggested that stakeholders in planning workshops focus on intergovernmental and cross-jurisdictional strategies. A consensus on focused strategies will (1) bring clarity to communication activity when stakeholders report back to their respective governmental and organizational leaders and (2) help establish an understanding of viable areas for collaboration and coordination. Additionally, the process will provide a new level of context for participating jurisdictions. With this context in hand, jurisdictions that move forward without regional resilience strategies will be better informed about regional and intergovernmental activity, interdependencies, and vulnerabilities.

When identifying the most impactful and effective strategies, it is important to bear in mind what is achievable. In this regard, the following attributes should be considered when evaluating and prioritizing individual strategies:

- Responsiveness to the scale and impact of likely hazards and vulnerabilities

- Ability to create movement toward identified performance goals for resilient infrastructure systems and critical operations

- Ability to address and strengthen interdependent infrastructure systems

- Administrative capacity needed for implementation 
- Available funding to implement capital projects or institutionalize resilience into existing activities

- Data and analysis required for implementation.

Workshop Activity 5 (Appendix D) helps guide the strategy prioritization process.

\subsection{Adoption, Implementation, and Funding}

Once a resilience strategy has been established, determining how to implement it, measure progress, and adjust the plan to ensure success will be critical. Implementation is a challenging part of the planning process, and it will require buy-in from all levels of organizations, as well as funding and resources to be effective. As a part of the adoption process, identifying a long-term coordinating structure to (1) track and evaluate ongoing implementation efforts and (2) ensure the conversation extends well beyond the initial planning period or creation will be critical to successful implementation.

Using effective communication methods and agreements for the intended audience will be essential (e.g., newspaper articles, memos, blogs, podcasts, internal messaging, and MOUs). Determining the audience and the best approach for communication are important. If agreements need to be signed, identifying the stakeholders that need to sign them and setting timelines for securing signatures is critical. Talking points and discussions will also be critical to this phase of the implementation process. Finding the messages that resonate with different stakeholders can help with effective communication.

\subsubsection{Implementation Action Plan}

Through the prioritization process, it may become possible to create an action plan for implementation. An action plan lays out the activity, describes the activity, estimates funding needs for implementation, identifies a responsible party, and establishes a timeline. An example of an action plan template is shown in Figure 9 to help guide the development process. This tactical tool can help communicate the strategy, track progress toward desired goals, and achieve metrics.

\section{RESILIENCE ACTION PLAN}

\begin{tabular}{|l|l|l|l|l|}
\hline Activity & Description & Estimated Funding (\$) & Responsible Party & Deadline \\
\hline & & & & \\
\hline & & & & \\
\hline & & & & \\
\hline
\end{tabular}

Figure 9. Example of a resilience action plan template

Institutionalizing the aspects of the plan into everyday activities is one of the most effective methods to implementing strategies. Ideally, management will be involved in the process, and funding will be allocated through existing budgets to support resilience measures and efforts. Once there is buy-in and implementation begins, having regular check-ins to track progress will be important. Working groups can establish regular meetings or calls to identify challenges, brainstorm solutions, and determine where others in the working group can provide support to overcome challenges. A team approach will 
ensure more success than if one entity is attempting to implement a resilience strategy alone.

Jurisdictions involved in regional resilience collaboration efforts can elect whether to adopt and/or otherwise integrate outputs of the planning process to varying degrees. Some may formally adopt the plan. Others may integrate principles from the plan, or resilience considerations, without formally adopting the plan. The following are examples of possible methods of resilience plan and/or strategy adoption and institutionalization:

- Integration of strategy and project in multi-stakeholder, cross-jurisdictional, nonbinding plan for city and agency adoption

- Integration into local planning efforts (e.g., zoning/land use, comprehensive, adaptation, energy, sustainability, and similar plans for guiding federal workplan/action plans)

- Institutionalization of the plan or resilience concept through working groups, agreements, MOUs, and funding/resource commitments between jurisdictions or between local governments and the state government.

\subsection{Funding Opportunities}

As mentioned above, more funding sources are becoming available to support resilience. In 2005, Natural Hazard Mitigation Saves: An Independent Study to Assess the Future Savings from Mitigation Activities, which was funded by FEMA, determined FEMA mitigation grants to have a benefit-cost ratio of $4: 1$. For every $\$ 1$ spent on mitigation, there was a $\$ 4$ return of avoided losses in the future. ${ }^{20,21}$

At the state level, there is an opportunity to institutionalize resilience and associated resilience performance metrics as a requirement for statefunded local projects and programs (examples may include how HUD Community Development Block Grant funds are administered at the state level). The integration of resilience performance standards and metrics can also include incentives during a competitive process (e.g., during funding opportunities for local governments or design firms).

Jurisdictions can, to some degree, integrate resilience principles into ongoing long-term

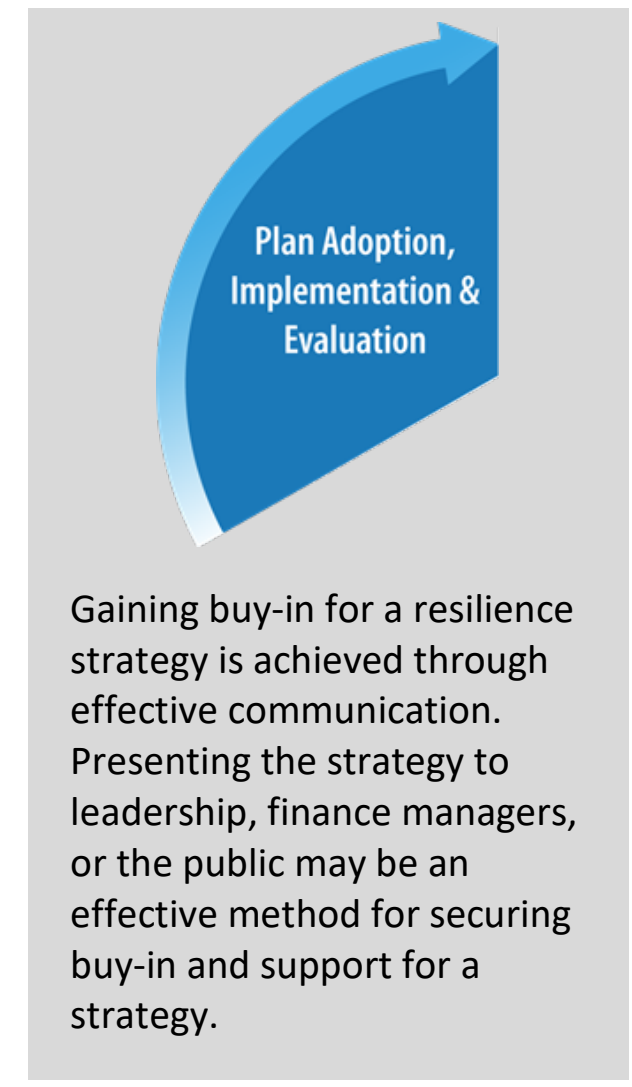
planning activities and the development and enforcement of certain policies and

\footnotetext{
${ }^{20}$ Multihazard Mitigation Council and National Institute of Building Sciences. Natural Hazard Mitigation Saves (2005), https://www.floods.org/PDF/MMC Volume1 FindingsConclusionsRecommendations.pdf

${ }^{21}$ In 2017 the study was updated and the ratio changed from 1:4 to 1:6. The interim and fully updated reports can be accessed at https://www.nibs.org/page/mitigationsaves.
} 
regulations. Additional resources, such as staff training and capacity building, will represent the predominant cost in the implementation of administrative or policy-based resilience strategies. Other costs include enforcement and evaluation, which will be a more sustained cost over a longer period of time.

At the local level, resilience strategies could be integrated into current planning policies and regulations, including:

- Building codes

- Development agreements

- Land acquisitions

- Overlay zoning

- Use-specific standards

- Point-of-sale disclosures.

Implementing strategies that take the form of programs and capital projects will incur higher costs that are representative of infrastructure and development projects. To this end, external funding, public finance opportunities, or both will need to be identified. The most common funding options currently in practice for resilient infrastructure include:

- Capital improvement plans

- Existing budgetary cycles

- Public-private partnerships

- Bond financing

- Clean energy financing institutions

- Grant funding.

\subsubsection{Public-Private Partnerships}

Public-private partnerships (PPP) have played an increasing role in the development of infrastructure projects nationwide. The integration of resilient measures and outcomes will need to be driven by the jurisdiction and/or interjurisdictional partners during development agreement negotiations with private partners. PPPs pose an opportunity for resilience to be integrated into a standard business-governmental transaction process. It should be noted that the power generation asset typically remains in the ownership of a third party rather than with the public entity. Recent research completed by HUD documents the expanded leverage and impact that a PPP yields. From the Summer/Fall 2015 issue of HUD's Evidence Matters:

An estimated $\$ 10$ in private sector loans, loan guarantees, and lines of credit can be leveraged for every $\$ 1$ of TIFIA [Transportation Infrastructure Finance and Innovation Act] funding. To date, PPP for infrastructure development have been concentrated in a handful of states; 20 states had no PPPs as of July 2014, and the 5 states with the highest number of PPPs have nearly twice the amount of per-capita project value as the next 20 states combined. The Build America Transportation Investment Center seeks to share best practices from high-performing states and broaden the impact of PPPs nationwide. The Interagency 
Infrastructure Finance Working Group, a group co-chaired by the secretaries of the U.S. Departments of Treasury and Transportation as part of the Build America Initiative, distilled some of those best practices into the following recommendations:

○ Increase resilience

- Employ "dig once" coordination of infrastructure projects to maximize efficiency and minimize disruption

Increase predevelopment funding

- Reform state laws to accommodate PPPs

- Improve permitting processes

$\circ$ Encourage pension fund investment

- Standardize PPP contracts

- Share risks effectively and bundle smaller projects to make them more attractive to institutional investors. ${ }^{22}$

\subsubsection{Bond Financing}

Bonds are a vital instrument for municipal capital improvements. They have been used as a familiar financing instrument for decades. Resilience can be integrated into the bond finance mechanism by various methods, including:

- General obligation bonds for capital improvement on public facilities

- Low-income housing bonds

- Private activity bonds

- School construction bonds

- $501 \mathrm{c}(3)$ eligible bonds (like nonprofit hospitals)

- Revolving loan funds

- Disaster recovery, resilient, or green infrastructure bonds (as shown in Figure 10).

${ }^{22}$ HUD, Evidence Matters (Summer/Fall 2015). https://www.huduser.gov/portal/sites/default/files/pdf/EMNewsletter-summer-fall-2015.pdf. 


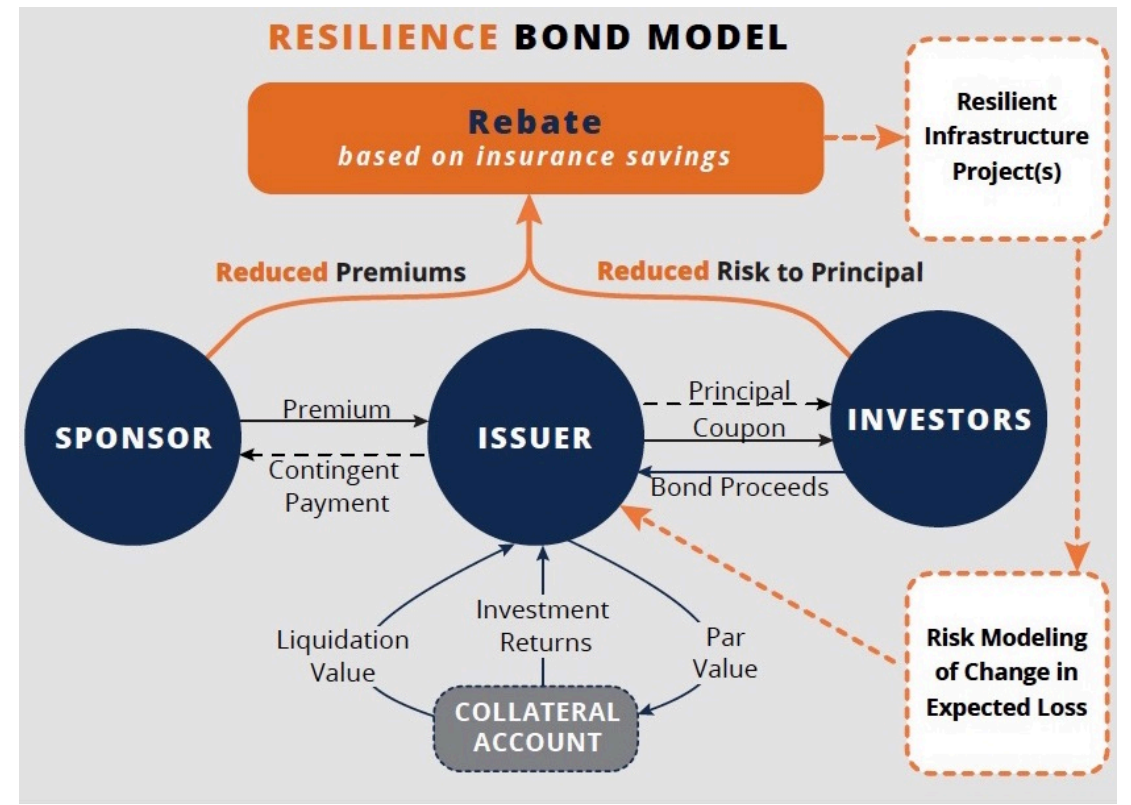

Figure 10. Example of a resilient/disaster recovery/green infrastructure bond model

Source: re:focus partners. Leveraging Catastrophe Bonds As a Mechanism for Resilient Infrastructure Finance (re:focus partners, RE.bound Program: 2015). http://www.refocuspartners.com/reports/RE.boundProgram-Report-December-2015.pdf.

\subsubsection{Clean Energy Financing Institutions}

State governments have played a role in disaster recovery and resilience implementation by developing public purpose financial institutions. By creating financial products to fund clean energy and resilience projects, these institutions can play a key role supporting state-wide resilient project implementation. Recent examples of such institutions include:

- New Jersey Energy Resilience Bank: http://www.state.nj.us/bpu/commercial/erb/ ${ }^{23}$

- Connecticut Green Bank: http://www.ctcleanenergy.com/

\subsubsection{Grant Funding}

The nonprofit sector has developed new resilience-facing grant programs, and these have included interest and funding from large philanthropies and foundations. In this space, The Rockefeller Foundation's 100 Resilient Cities is a program that features support for resilience planning and project implementation. ${ }^{24}$

Increasingly, federally administered grant programs (e.g. HUD National Disaster Resilience Competition) are addressing and funding resilience projects outright, or they are incorporating resilience as a scoring criteria and/or mandatory component of grant selection and award. Anticipated effects of this trend indicate that agencies tied to critical

\footnotetext{
${ }^{23}$ New Jersey Energy Resilience Bank Grant and Loan Financing Program Guide: ERB Financing Program Guide (October 14, 2014). http://www.state.nj.us/bpu/pdf/erb/Final\%20ERB\%20Program\%20Guide.pdf.

${ }^{24}$ To learn more about the 100 Resilient Cities program visit the website at https://www.100resilientcities.org/.
} 
infrastructure such as the U.S. Department of Transportation, the U.S. Environmental Protection Agency (EPA), and DOE will be using resilience as a metric and requirement in the near future.

States also have the opportunity to develop innovative grant programs. These programs can support the deployment of certain technologies throughout a state as pilots and demonstration projects. Examples of innovative resilient grant programs include:

- Massachusetts Community Clean Energy Resiliency Initiative: http://www.mass.gov/eea/energy-utilities-clean-tech/renewableenergy/resilience/resilience-initiative.html

- Connecticut Microgrid Grant and Loan Program: http://www.ct.gov/deep/cwp/view.asp?a $=4405 \& Q=508780$

\subsubsection{Insurance Considerations}

The insurance industry is also adopting and implementing measures that directly tie to resilience. Increasingly, premium costs will be realigned to reflect broader impacts of changing threats. Site-level resilience improvements to infrastructure and the built environment will be reflected in rate structures and risk management strategies.

\subsubsection{Resources for Resilience Financing}

Each of these types of financing and funding streams is well researched, and governments are well served by exploring published guidebooks and reports on each. The following resources provide a snapshot of work completed in the finance and funding space:

- Leveraging Catastrophe Bonds: As a Mechanism for Resilient Infrastructure Finance (funded by The Rockefeller Foundation) ${ }^{25}$

- Returns on Resilience: The Business Case 26

- Resilient Power: Financing for Clean, Resilient Power Solutions ${ }^{27}$

- (EPA Water Infrastructure and Resiliency Finance Center: http://www.epa.gov/waterfinancecenter

\subsubsection{Assessment and Evaluation}

Using the performance goals established following the guidelines provided in Section 3.4.1.3, stakeholders can assess the progress of the resilience strategy and evaluate its effectiveness. There are currently no official resilience-specific metrics, but NIST is developing metrics that can be used more broadly. In the meantime, a working group or stakeholder group may choose to use meaningful assessment criteria, for example reducing the number of hours a critical facility is without power or increasing the number

\footnotetext{
25 re:focus partners. Leveraging Catastrophe Bonds: As a Mechanism for Resilient Infrastructure Finance (re:focus partners, RE.bound Program: 2015). http://www.refocuspartners.com/reports/RE.bound-ProgramReport-December-2015.pdf

${ }^{26}$ Urban Land Institute. Returns on Resilience: The Business Case (Washington, D.C.: Urban Land Institute, Center for Sustainability, 2015). http://uli.org/wp-content/uploads/ULI-Documents/Returns-onResilience-The-Business-Case.pdf.

${ }^{27}$ Robert G. Sanders, Resilient Power: Financing for Clean, Resilient Power Solutions (Montpelier, VT: Clean Energy Group, 2014). https://www.cleanegroup.org/wp-content/uploads/CEG-Financing-forResilient-Power.pdf.
} 
of access routes to a critical facility, such as a hospital or community shelter. By prioritizing what is important to the region, the stakeholders, and a community, the metrics needed to measure success of resilience projects will become apparent.

Throughout the implementation and assessment process, it is essential to remember that the resilience strategy is a work in progress. Resilience is a fairly new concept that takes practice and requires that roles, responsibilities, and funding be institutionalized. To improve the process, the working group would need to reevaluate what works well, where there are challenges, and how to overcome those challenges. In doing so, a regional resilience planning group could use the lessons learned to create a newer and better version of a resilience plan for future use. It would be beneficial to evaluate resilience activities annually and the resilience plan every few years. Establishing a time frame for revisiting the planning process will help formalize that step and ensure the conversation continues to enhance regional resilience. 


\section{Conclusion}

Changes in threats and vulnerabilities are creating challenges across the country, and resilience efforts to improve national security, energy and water security, economic wellbeing, and quality of life are underway. The Resilience Roadmap was created in an effort to (1) summarize the lessons learned through CEQ preparedness pilot in the State of Colorado and (2) outline a process that can be replicated by other communities with resilience or preparedness goals. One of the main lessons learned through stakeholder engagement is that it is important to have the right stakeholders involved in the conversation.

\subsection{A Replicable Process}

The Resilience Roadmap demonstrates the key points of an interagency, multijurisdictional process for resilience planning. The roadmap is a type of strategic plan that outlines goals, desired outcomes, and activities to be taken over specified time frames to increase resilience within a region or a system. The roadmap identifies ways to outline tasks and priorities for action, and it allows progress to be tracked.

The steps to creating a resilience plan include intergovernmental coordination and preparation, strategy development and adoption, implementation and evaluation of the effectiveness of solutions. Though the road-mapping process was originally intended to target preparedness to specific hazards and threats, it became evident during the pilot process that a plan that is not threat-specific would be the most widely replicable, especially if it addressed resilience more broadly. The process is the same whether an organization is mitigating against human-caused threats to infrastructure or weatherrelated hazards - in both cases, the goal is to mitigate the effects of a potential threat.

A successful resilience strategy can be designed by establishing a working group, identifying desired outcomes and goals, undertaking the planning process, preparing for stakeholder engagement, and ensuring the right players are involved in the discussionfrom local, state, and federal government representatives to utility service providers. Creating a plan, implementing it, and evaluating its success in order to improve the plan are also essential. Though the initial planning phase is the longest portion of the Resilience Roadmap process, keeping plan implementation and improvement in sight is essential.

Using existing planning tools, processes, and resources will help stakeholders develop effective plans. Because threats and impacts are not bound by jurisdictional lines, multijurisdictional resilience planning can foster integrated approaches and maximize available resources. To foster such engagement, the Resilience Roadmap provides a strategic framework for collaboration among local, state, and federal governments. By implementing the resilience planning process, regional stakeholders can work together to strengthen resistance to disruptive events and improve the capacity to recover from them safely, securely, and promptly. 


\section{Bibliography}

Adams, Christopher R. Adams. n.d. "Impacts of Temperature Extremes." Fort Collins, CO: Cooperative Institute for Research in the Atmosphere, Colorado State University. http://sciencepolicy.colorado.edu/socasp/weather1/adams.html.

Amin, Massoud. 2002. "Toward Secure and Resilient Interdependent Infrastructures." J. Infrastruct. Syst. 8(3): 67-75.

Avalon, Mitch. 2008. Low Impact Development (LID) and Flood Control. Contra Costa County Flood Control and Water Conservation District.

http://www.coastal.ca.gov/nps/lid/6Avalon-LIDandFloodControl.pdf.

Campbell, Richard J. 2012. Weather-Related Power Outages and Electric System Resiliency. Congressional Research Service. http://fas.org/sgp/crs/misc/R42696.pdf.

Colorado Division of Water Resources. 2012. Rainwater Collection in Colorado.

CUNY (City University of New York). 2014. Strategies for Integrating Solar and Distributed Generation for Emergency Power and Resiliency Deployment. Sustainable CUNY.

DOE (U.S. Department of Energy). 2013. Grid Energy Storage. http://energy.gov/sites/prod/files/2013/12/f5/Grid\%20Energy $\% 20$ Storage $\% 20 \mathrm{December}$ \%202013.pdf.

ESA (Energy Storage Association). 2014. "Electricity Storage and Plug in Vehicles." http://energystorage.org/energy-storage/technology-applications/electricity-storage-andplug-vehicles.

Haught, Debbie, and Joseph Paladino. 2012. "Improving the Reliability and Resiliency of the US Electric Grid." Smart Energy.

http://energy.gov/sites/prod/files/Improving $\% 20$ the $\% 20$ Reliability $\% 20$ and $\% 20$ Resiliency $\% 20$ of $\% 20$ the $\% 20$ US $\% 20$ Electric $\% 20 \mathrm{Grid} \% 20$ -

\%20SGIG $\% 20$ Article $\% 20$ in $\% 20$ Metering $\% 20$ International $\% 20$ Issue $\% 201 \% 202012$.pdf.

Johnson, Bradley W. 2005. After the Disaster: Utility Restoration Cost Recovery. Washington, D.C.: Edison Electric Institute. Exhibit MP1.

https://www.efis.psc.mo.gov/mpsc/commoncomponents/viewdocument.asp?DocId=4048 $\underline{185}$.

Kelly, Morgan. 2014. "Two Years after Hurricane Sandy, Recognition of Princeton's Microgrid Still Surges." News at Princeton. http://www.princeton.edu/main/news/archive/S41/40/10C78/.

National Institute of Building Sciences. 2014a. "High Performance-Based Design for Buildings." http://www.nibs.org/?page=irdp_projects.

. 2014b. "Integrated Resilient Design Program.” http://www.nibs.org/?page=irdp. 
—. 2014b. "Whole Building Design Guide: Natural Hazards Mitigation." http://www.wbdg.org/design/resist_hazards.php.

-2013. Dialogue on National Resilience held at the National Institute of Building Sciences: Summary Report.

http://c.ymcdn.com/sites/www.nibs.org/resource/resmgr/IRDP/Dialogue_on_National_R esilie.pdf.

NOAA (National Oceanic and Atmospheric Administration). 2014. "National Oceanic and Atmospheric Administration's Hydrologic Information Center: Flood Loss Data." http://www.nws.noaa.gov/hic/.

NREL (National Renewable Energy Laboratory). 2014. Distributed Solar PV for Electrical System Resiliency: Policy and Regulatory Considerations. Golden, CO:

National Renewable Energy Laboratory. NREL/BR-6A20-62631.

http:/www.nrel.gov/docs/fy15osti/62631.pdf.

Resilient Design Institute. 2013. "Resilient Design Strategies."

http://www.resilientdesign.org/resilient-design-strategies/.

ResilientCity. 2012. "Resilient Design Principles."

http://www.resilientcity.org/index.cfm?pagepath=Resilience/Resilient_Design_Principles

$\underline{\text { \&id }=11900 .}$.

Singer, M. 2014. "Resilience is the Next Step on the Path Toward

Sustainability." American Institute of Architects.

St. John, Jeff. 2014. "Drought Reveals Water-Energy Connection, Cutting California's Hydropower in Half." Greentech Media.

http://www.greentechmedia.com/articles/read/Drought-Reveals-Water-Energy-

Connection-Cutting-Californias-Hydropower-in.

Stockholm Environment Institute. 2010. Rainwater Harvesting: A Lifeline for

Human Well-Being. 2010. Nairobi, Kenya: United Nations Environment Programme

(UNEP) Division of Environmental Policy Implementation.

http://wedocs.unep.org/handle/20.500.11822/7762.

Urban Green Council. 2014. "Designing for Resiliency."

http://urbangreencouncil.org/content/events/designing-resiliency.

USDOT. 2014. "Resilience Projects in Response to Hurricane Sandy." http://www.fta.dot.gov/15138 16147.html.

York, Dan, Martin Kushler, and Patti Witte. 2007. Examining the Peak Demand Impacts of Energy Efficiency. Washington, D.C.: American Council for an Energy Efficient Economy. https://aceee.org/research-report/u072. 


\section{Appendix A. Definitions of Resilience}

A few examples of definitions for resilience are listed for reference.

Executive Order 13693 defines resilience "the ability to anticipate, prepare for, and adapt to changing conditions and withstand, respond to, and recover rapidly from disruptions."

DOE's Office of Electricity defines resilience as "the ability of an energy facility to recover quickly from damage to any of its components or to any of the external systems on which it depends."

Resilience is defined in the Presidential Policy Directive 21 as the ability to prepare for and adapt to changing conditions and withstand and recover rapidly from disruptions. Resilience includes the ability to withstand and recover from deliberate attacks, accidents, or naturally occurring threats or incidents.

The Rockefeller Foundation's 100 Resilient Cities defines urban resilience as "the capacity of individuals, communities, institutions, businesses, and systems within a city to survive, adapt, and grow no matter what kinds of chronic stresses and acute shocks they experience."

The Colorado Resiliency and Recovery Office defines resilience as "the ability of communities to rebound and positively adapt to or thrive amidst changing conditions or challenge and maintain quality of life, healthy growth, economic vitality, durable systems and conservation of resources for present and future generations."

NIST has several definitions for resilience in its Community Resilience Planning Guide for Buildings and Infrastructure Systems; these resulted from a series of stakeholder group meetings.

NREL developed a definition while developing the Resilience Roadmap, defining resilience as "the ability to anticipate, prepare for, and adapt to changing conditions and withstand, respond to, and recover rapidly from disruptions through adaptable and holistic planning and technical solutions". 


\section{Appendix B. Resources}

\section{Resources for Intergovernmental Stakeholder Engagement and Assessments}

The International City/County Management Association's Collaborative Service Delivery compiles resources representing best practices for delivering collaborative and alternative services. Documents provided on the website are designed to assist local governments in addressing current challenges through new and innovative approaches to service delivery through public-private partnerships, public-public partnerships. and other forms of collaboration. ${ }^{28}$

DHS's Regional Resilience Assessment Program (RRAP) is a cooperative assessment of specific critical infrastructure within a designated geographic area and a regional analysis of the surrounding infrastructure to address a range of infrastructure resilience issues that could have regionally and nationally significant consequences. These voluntary, nonregulatory RRAP projects are led by DHS and are selected each year by the Department with input and guidance from federal, state, and local partners. ${ }^{29}$

FEMA's Threat and Hazard Identification and Risk Assessment (THIRA) is a risk assessment process that helps communities identify what threats and hazards can affect a community and the impacts associated with those threats and hazards. The THIRA helps communities understand their risks and determine the level of capability they need in order to address those risks. ${ }^{30}$

\section{Resources for Resilience Baselining}

Forecasting the impact of changing threats and the degree to which a jurisdiction is prepared for unforeseen system stress is a complex task. However, interjurisdictional /intergovernmental collaboration benefits when communities have already evaluated their resilience and established a baseline. To support this task, the Climate Smart Resiliency Planning tool ${ }^{31}$ is a resource that communities may find useful. Although the tool targets communities in New York State specifically, its framework is fairly universal.

Additional resources that support community resilience planning for critical infrastructure include:

\section{- DOE's Guide to Community Energy Strategic Planning ${ }^{32}$}

\footnotetext{
${ }^{28}$ ICMA. "Collaborative Service Delivery." http://icma.org/en/results/management_strategies/resources/documents_articles\#collaborative-servicedelivery.

${ }^{29}$ RRAP Fact Sheet: https://www.dhs.gov/publication/rrap-fact-sheet

${ }^{30}$ FEMA THIRA Overview: https://www.fema.gov/threat-and-hazard-identification-and-risk-assessment

${ }^{31}$ New York State Climate Smart Communities, Climate Smart Resiliency Planning. A Planning Evaluation Tool for New York State Communities: Version 2.0 (October 2014). http://www.dec.ny.gov/docs/administration_pdf/csrptool.pdf

${ }^{32}$ DOE. Guide To Community Energy Strategic Planning. (U.S. Department of Energy, Office of Energy Efficiency and Renewable Energy, 2013), http:/energy.gov/sites/prod/files/2014/05/f15/cesp_guide.pdf.
} 
- EPA's Being Prepared for Climate Change: A Workbook for Developing RiskBased Adaptation Plans, pages 35-50 33

- EPA's Climate Ready Water Utilities initiative provides water utility managers with the tools, training, and technical assistance needed to adapt to change. It also provides a clear understanding of science and adaptation options for the water sector. ${ }^{34}$

- NOAA's Coastal Resilience ${ }^{35}$ represents an approach—enabled by a suite of interactive tools - that supports decisions to reduce the ecological and socioeconomic risks of coastal hazards. Users have access to interactive tools to visualize future flood risks from sea level rise and storm surge. Additional tools can help users identify areas and populations at risk from coastal hazards and gain a better understanding of ecological, social, and economic impacts. This information is particularly helpful for officials involved in coastal planning, zoning, and land acquisition who must consider rising sea levels and increased storm intensity and frequency.

- NOAA's Hazards U.S. Multi-Hazard (HAZUS-MH) is a nationally applicable standardized method that estimates potential losses from earthquakes, hurricane winds, and floods. It uses state-of-the-art GIS software to map and display hazard data and estimates of damage and economic loss to buildings and infrastructure. ${ }^{36}$

\footnotetext{
${ }^{33}$ EPA. Being Prepared for Climate Change: A Workbook for Developing Risk-Based Adaptation Plans (Climate Ready Estuaries, EPA Office of Water, 2014). http://www.epa.gov/sites/production/files/201409/documents/being prepared workbook 508.pdf.

${ }^{34}$ EPA. "Climate Ready Water Utilities (CRWU)." http://water.epa.gov/infrastructure/watersecurity/climate/.

${ }_{35}$ NOAA. "Coastal Resilience Mapping Portal.” http://coast.noaa.gov/digitalcoast/tools/coastalresilience and https://maps.coastalresilience.org/.

${ }^{36}$ NOAA. "Hazards U.S. Multi-Hazard (HAZUS-MH)." (NOAA Office of Digital Management: Digital Coast). https://coast.noaa.gov/digitalcoast/.
} 


\section{Appendix C. Energy Profile Exercise}

The energy profile exercise in this appendix provides an example of the type(s) of information to collect, where it can be found, and how it can be aggregated to inform energy resilience strategies for communities or campuses. The content has been adapted from DOE's Guide to Community Energy Strategic Planning. ${ }^{37}$

\section{Data Sources for Information on Current Energy Use (Baseline)}

\section{Government Operations}

\section{Buildings}

- Ask the department of public works or finance manager for annual fuel and utility bills for all the local government's buildings, along with building size information, and calculate energy use per square foot. If energy bill management is more decentralized in your jurisdiction, you may need to work with individual departments or your local utility to obtain this information.

- Convert various fuel usage data to a standard unit (typically Btu) to compare across type. ${ }^{38}$

- Relevant metrics are provided in the Table C-1. It is often appropriate to standardize use and cost by building or department, as budget authority will be at this level.

- Aggregate data into collections of buildings, departments, campuses, and other categories if they will be managed together.

Table C-1. Example of a Table of Energy Profile Data

\begin{tabular}{|c|c|c|c|c|}
\hline Metric & Electricity & Natural Gas & Heating Oil & $\begin{array}{l}\text { Propane/Other } \\
\text { (e.g., Wood) }\end{array}$ \\
\hline Cost & $\$ / y r$. & $\$ / y r$. & $\$ / y r$. & $\$ / y r$. \\
\hline Energy Use & $\mathrm{kWh} / \mathrm{yr}$. & therms/yr. & gallons/yr. & gallons/yr. \\
\hline Convert to: & MMBtu & MMBtu & MMBtu & MMBtu \\
\hline Building Area & total sq. $\mathrm{ft}$. & total sq. ft. & total sq. ft. & total sq. ft. \\
\hline Standardized Use & MMBtu/sq. ft. & MMBtu/sq. ft. & MMBtu/sq. ft. & MMBtu/sq. ft. \\
\hline Standardized Cost & $\$ / s q . f t$. & $\$ / s q . f t$. & $\$ / s q . f t$. & $\$ / s q . f t$. \\
\hline
\end{tabular}

kWh = kilowatt-hours; MMBtu = million British thermal units

\footnotetext{
${ }^{37}$ U.S. Department of Energy, Guide To Community Energy Strategic Planning (Washington, D.C.:

U.S. Department of Energy, 2013) https://www.energy.gov/sites/prod/files/2014/05/f15/cesp guide.pdf.

${ }^{38} \mathrm{http}$ ://energy.gov/sites/prod/files/2014/05/f16/cesp_tool_4-

1_energy_data_calculation_and_summary_tool.xlsx
} 


\section{Vehicle Fleet and Other Transportation}

- Ask the department of public works for annual fuel consumption data (e.g., for diesel, gasoline, liquid and petroleum gas) and miles traveled for the local government's fleet vehicles, and then calculate the fleet average miles per gallon. Be sure to include off-road vehicles, such as snowplows, mowers, boats, and any other vehicular sources of fuel consumption.

- Relevant metrics are provided in Table C-2. It is often appropriate to standardize use and cost by department.

- Aggregate the data into collections of vehicles or equipment if they will be managed together-by department or other budget-line division.

Table C-2. Example of a Table of Fuel Data

\begin{tabular}{|l|l|l|l|}
\hline Metric & Diesel & Gasoline & Natural Gas \\
\hline Cost & $\$ / y r$. & $\$ / y r$. & $\$ / y r$. \\
\hline Volume & gallons/yr. & gallons/yr. & gallons/yr. \\
\hline Distance & miles/yr. & miles/yr. & miles/yr. \\
\hline Standardized use & miles/gallon & miles/gallon & miles/gallon \\
\hline
\end{tabular}

\section{Community Operations}

\section{Community Buildings}

- Ask the manager of the department of public works or the finance department to provide a referral to the local government's key account manager or managers for the local utility or utilities. Ask account managers for annual energy usage for the jurisdiction's ZIP code or codes by market sector (i.e., residential, commercial, institutional, and industrial).

- Collect census information from local government offices or search the U.S. Census Bureau's American Fact Finder for specific local information. ${ }^{39}$

- Ask appropriate stakeholders for additional data they think will be helpful, including commercial or institutional facility managers, school district financial officers, large industrial users' trade associations, renewable energy vendors, and homebuilders. Information on heating oil, propane, and other fuels may come from fuel dealers' trade associations.

- Collect the same, relevant metrics for government buildings if possible.

- When appropriate, aggregate the collected data by sector (i.e., residential, commercial, institutional, and industrial). Remove information on specific businesses or institutions if they have set separate targets as part of the plan. ${ }^{40}$

\footnotetext{
${ }^{39}$ U.S. "Census Bureau, American Fact Finder," http://factfinder2.census.gov/faces/nav/jsf/pages/index.xhtml.

${ }^{40}$ State energy profiles - including national, state, and limited local electricity data on production, consumption, cost, and expenditures - can be found at the U.S. Energy Information Administration (EIA) "State Profiles and Energy Estimates" website at https://www.eia.gov/state/. For building-specific energy information - including summaries of typical building categories (e.g., residential and commercial) and the types of energy they use - can be found at EIA's "Residential Energy Consumption Survey (RECS)" website at https://www.eia.gov/consumption/residential/ and its "Commercial Buildings Energy
} 


\section{Community Transportation}

- Check with the city's and state's transportation departments and any regional planning associations for recommendations on data sources and appropriate questions to answer.

- A few broad variables are related to transportation energy use:

○ Number and efficiency of vehicles: Check with your state's transportation department $^{41}$

○ Transportation fuels (consumption and cost): Check with your state's energy office ${ }^{42}$

- Also collect data about:

- Travel behavior (vehicle miles traveled (total and per household), choice of transportation mode, etc.) and related fuel consumption

- Energy consumption data broken down by end-use sector (transportation, residential and commercial buildings, city and public sector, industry, electricity generation, heating, water, and waste) in MMBtu

- Load profiles for residential and commercial buildings that are indicative of the area's general energy use

- Industrial-load data for major, local, industrial energy users

- Local transportation-fleet characteristics (vintage, efficiency, and vehicle type).

\section{Electricity Generation and Utility Data}

- Existing grid-mix by generation type: coal, natural gas, hydro, and non-hydro renewables

- Utility type: publicly owned (muni/co-op) versus investor-owned utility

- Current policies and rates applicable to renewable energy or distributed energy resources (e.g., net energy metering, capacity-based incentives, performance based incentives, local tax incentives).

\footnotetext{
Consumption Survey (CBECS)" at https://www.eia.gov/consumption/commercial/. Petroleum dataincluding national, state, and limited local fuel data on production, consumption, cost, and expendituressee EIA's "Petroleum and Other Liquids" website at https://www.eia.gov/petroleum/.

${ }^{41}$ Federal Highway Administration. "State Transportation Web Sites."

https://www.fhwa.dot.gov/webstate.cfm

42 NASEO (National Association of State Energy Officials). "NASEO State and Territory Energy Offices." http://www.naseo.org/members-states
} 


\section{Energy Cost Information}

- Average electricity rates in $\$ / \mathrm{kWh}$ (typically residential, commercial, and industrial)

- Utility tariff structure (e.g., demand charges, block charges, $\mathrm{kWh}$ charges, and peak demand)

- Average prevailing heating costs (residential, commercial, and industrial).

\section{From Energy Profile to Resilient Strategies}

The energy baseline, as shown in Figure $\mathrm{C}$-1, gives context and insights into where energy is consumed throughout a jurisdiction. The baseline establishes how much electricity, natural gas, and fuel are needed for critical operations, government functions, and overall community functionality. A baseline is essential in developing rational, proactive, and resilient preparedness strategies.

\section{City Energy Profile for Golden, Colorado}

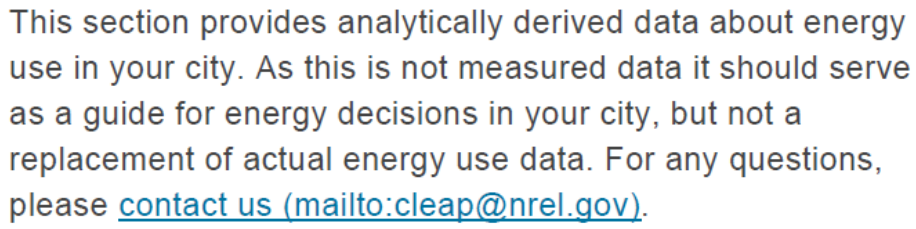

Electricity Statistics for Golden, Colorado in 2013

\section{ELECTRICITY USAGE (MWH)}

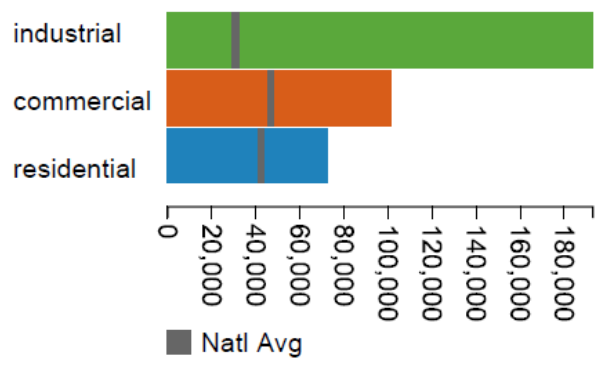

Modeled data for many of the energy cost information bullets can be obtained for local jurisdictions using the State and Local Energy Data (SLED) tool, which can be found at the following link: www.eere.energy.gov/sled/

An example of a city energy profile using the SLED too is provided for Golden, Colorado in Figure C-1. 
With an accurate energy profile available, resilience strategies become more specific and accurate. Using an energy use profile for strategic resilience development brings another level of clarity to the effort, and doing so would help planners understand, for example:

- How much power for on-site generation and backup systems would be needed to maintain critical operations like police stations, fire stations, schools and hospitals

- How much fuel is needed to maintain the viability of critical transportation systems, including emergency response and public transportation

- How much power for on-site and backup systems would be needed to maintain the operation of interrelated infrastructure systems like water and wastewater treatment and IT and communication services

Table C-3 is a checklist of jurisdictional planning documents that may be useful while conducting a resilience assessment and planning efforts. 
Table C-3. Checklist of Jurisdictional Plans ${ }^{a}$

\begin{tabular}{|c|c|c|c|c|c|}
\hline & Plan Ordinance or Code & $\begin{array}{r}A v \\
\text { Yes }\end{array}$ & & $\begin{array}{l}\text { Adoption } \\
\text { Year }\end{array}$ & $\begin{array}{l}\text { Next Update } \\
\text { Due }\end{array}$ \\
\hline 1.1 & Municipal Comprehensive Plan & & & & \\
\hline 1.2 & Zoning Ordinance & & & & \\
\hline 1.3 & Subdivision Ordinance & & & & \\
\hline 1.4 & Open Space Plan & & & & \\
\hline 1.5 & Natural Resource Conservation Plan & & & & \\
\hline 1.6 & Stormwater Management Plan & & & & \\
\hline 1.7 & Coastal Plan or Element in Other Plan & & & & \\
\hline 1.8 & Shoreline Restoration Plan & & & & \\
\hline 1.9 & $\begin{array}{l}\text { Coastal Erosion Hazard Area } \\
\text { Ordinance }\end{array}$ & & & & \\
\hline 1.10 & Multi-Hazard Mitigation Plan & & & & \\
\hline 1.11 & Flood Plain Management Plan & & & & \\
\hline 1.12 & Flood Damage Prevention Ordinance & & & & \\
\hline 1.13 & Evacuation Plan & & & & \\
\hline 1.14 & $\begin{array}{l}\text { Emergency Response and Short- } \\
\text { Term Recovery Plan }\end{array}$ & & & & \\
\hline 1.15 & Continuity of Operations Plan & & & & \\
\hline 1.16 & Disaster Recovery Plan & & & & \\
\hline 1.17 & Long-Term Recovery Plan & & & & \\
\hline 1.18 & $\begin{array}{l}\text { Economic Development Plan or } \\
\text { Strategy }\end{array}$ & & & & \\
\hline 1.19 & Capital Improvements Plan & & & & \\
\hline 1.20 & Metropolitan Transportation Plan & & & & \\
\hline 1.21 & Historic Preservation Plan & & & & \\
\hline 1.22 & Local Waterfront Revitalization Plan & & & & \\
\hline 1.23 & Mitigation Plan & & & & \\
\hline 1.24 & Energy Considerations & & & & \\
\hline 1.25 & Water Operations & & & & \\
\hline 1.26 & Other & & & & \\
\hline
\end{tabular}

a New York State Climate Smart Communities, Climate Smart Resiliency Planning: A Planning Evaluation Tool for New York State Communities Version 2.0 (New York State Climate Smart Communities, 2014) http://www.dec.ny.gov/docs/administration pdf/csrptool.pdf. 


\section{Appendix D. Workshop Discussion Questions and Tools}

This appendix provides questions and tools that can be used in resilience and preparedness planning workshops. The questions and tools are presented for five important tasks:

- Analyzing interdependencies

- Identifying vulnerabilities

- Setting performance goals

- Developing a resiliency strategy

- Prioritizing strategies

\section{Activity 1: Analyzing Interdependencies}

\section{Discussion Questions}

- Where do critical infrastructure systems cross jurisdictional boundaries?

- How have stakeholder jurisdictions or governments planned for system redundancy and flexibility, system failure or outage?

- Which governmental operations rely infrastructure systems owned and operated by other entities?

- What is the relationship of infrastructure systems providers and buyers between each participating jurisdiction and governmental entity?

- What are shared assets and capabilities?

Discussion Tool

Facilitators can use the worksheet in Figure D-1 to frame and record the discussion. 


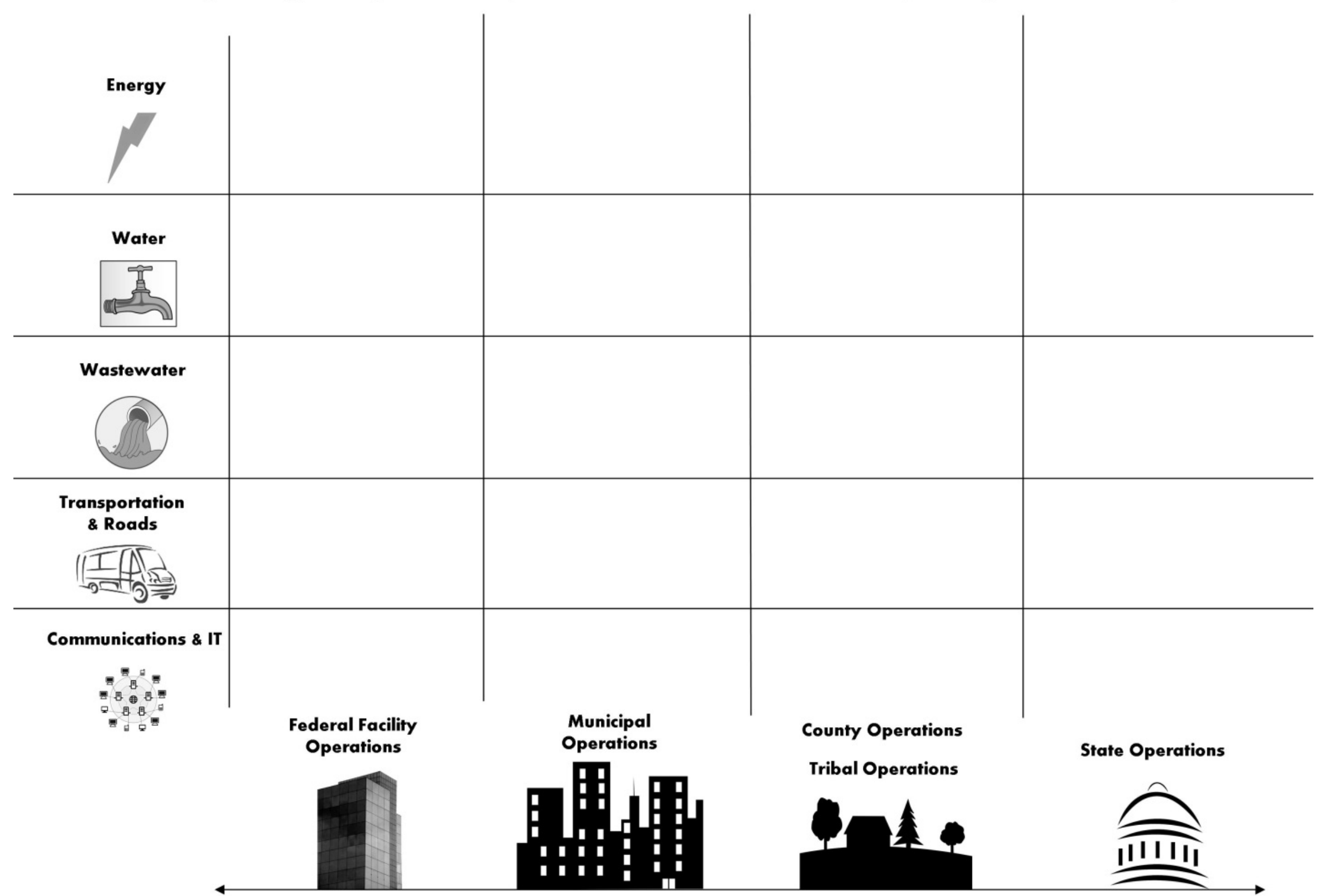

Figure D-1. Activity 1: Sample worksheet for facilitators 


\section{Activity 2: Identifying Vulnerabilities}

\section{Discussion Questions}

- What are the natural hazards and threats that jurisdictions share?

- How current is risk information for your communities (e.g., flood plain and hydrology information)

- How common are the hazards and threats? What is the frequency of their occurrence?

- Which infrastructure systems have been impacted by past natural hazards or system shocks?

- How long did critical infrastructure remain off-line or in a reduced operational state?

- Which system failures would have the greatest impact on the health and wellbeing of community members?

- What was the subsequent impact on critical government operations? What was the impact on broader-scale community or campus activity?

- How did the compromised infrastructure systems impact jurisdictions or governments involved?

- Which natural hazards and system shocks are anticipated to increase at the regional level in the future?

Discussion Tool

Facilitators can use the worksheet in Figure D-2 to frame and record the discussion. 


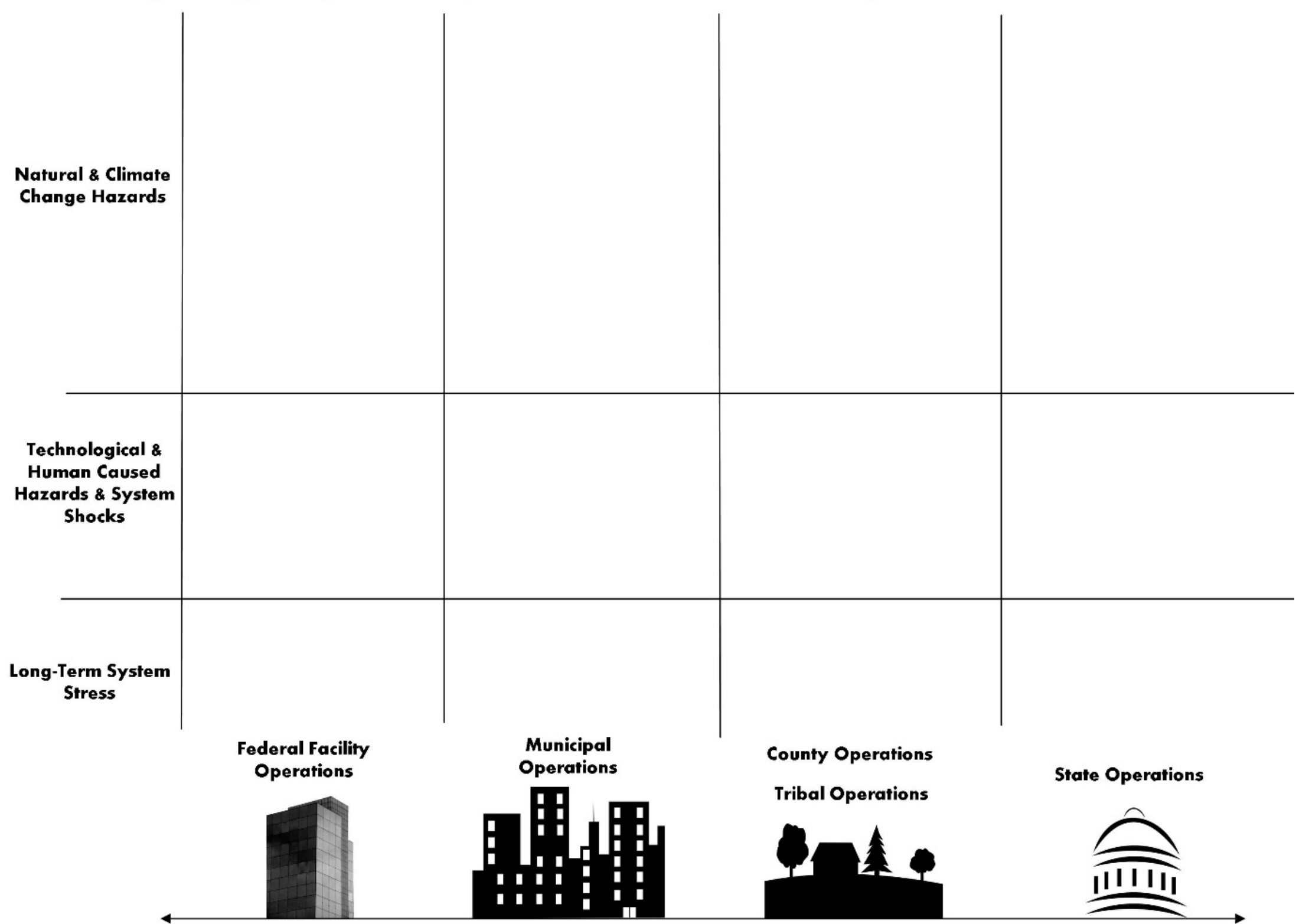

Figure D-2. Activity 2: Sample worksheet for facilitators 


\section{Activity 3: Setting Performance Goals}

Discussion Questions

- Given the interdependencies and vulnerabilities that have been identified, which shared infrastructure systems might likely be impacted in the next 20-30 years? How does interruption to these infrastructure systems impact the jurisdictions and government operations involved?

- Who is responsible as the owner and operator of these infrastructure systems?

- What is the current recovery time for system-wide infrastructure recovery? What are the performance goals for accelerated system-wide recovery?

- What are the gaps and barriers that exist between current recovery time and the performance goal, including resources, policies, agreements, technology gaps, human capacity and system integration?

Discussion Tool

Facilitators can use the worksheet in Figure D-3 to frame and record the discussion. 


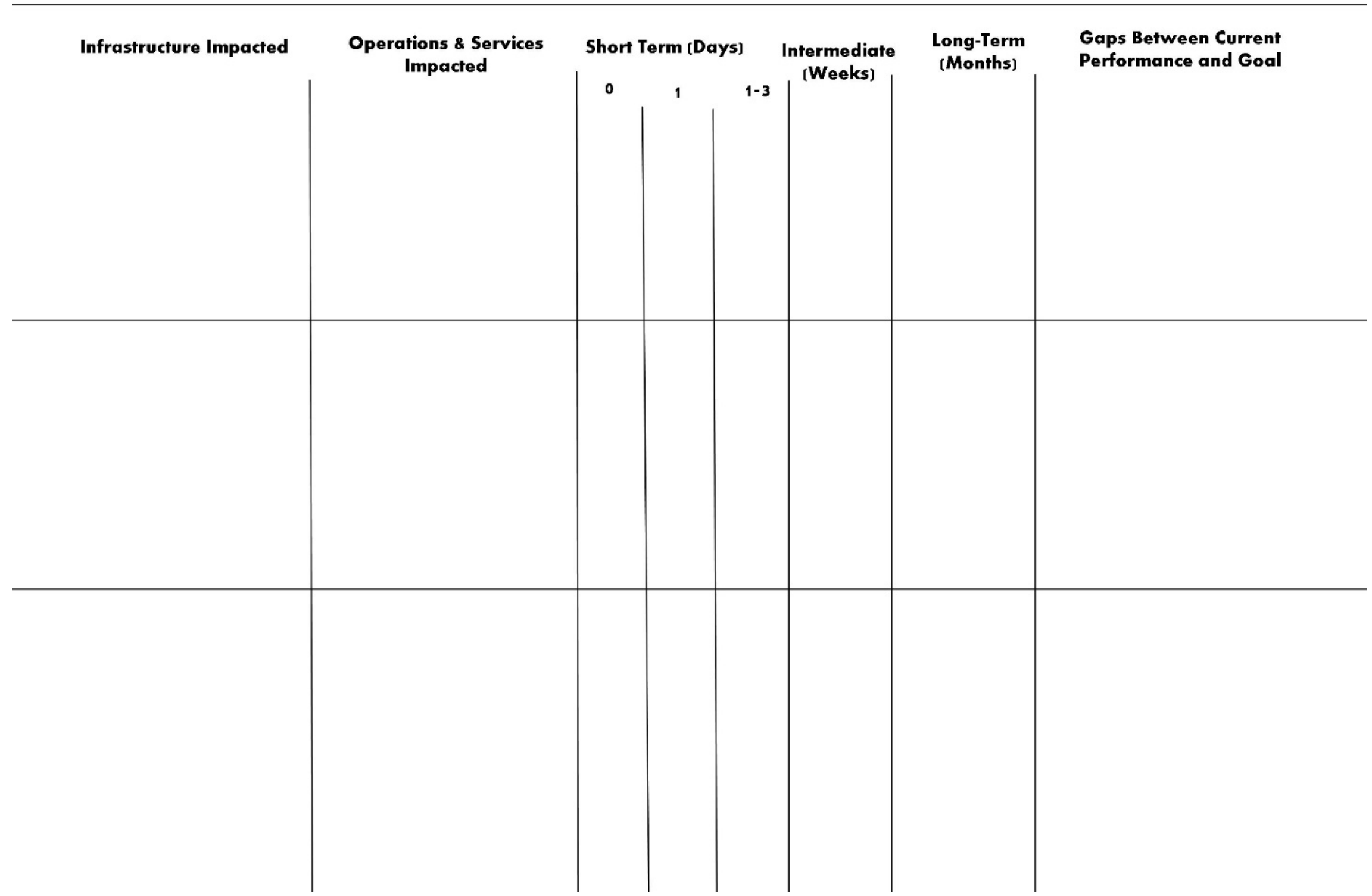

Figure D-3. Activity 3: Sample worksheet for facilitators 


\section{Activity 4: Developing a Resilience Strategy}

Discussion Questions

- Which strategies support a greater ability to maintain the operability of shared infrastructure system-wide during system shock and stress?

- Which strategies yield a co-benefit across jurisdictional lines and/or provide a downstream benefit for other infrastructure system users?

- Have all strategy categories been considered, including long-term planning, regulations and policies, programs, and capital projects?

- Which strategies support a specific site or critical government operation rather than a broader system or regional resilience? Which site-specific/government operation-specific solutions could be scaled throughout a jurisdiction for broader community resilience? Which solutions could be scaled across jurisdictional boundaries for regional resilience?

Discussion Tool

Facilitators can use the worksheet in Figure D-4 to frame and record the discussion. 


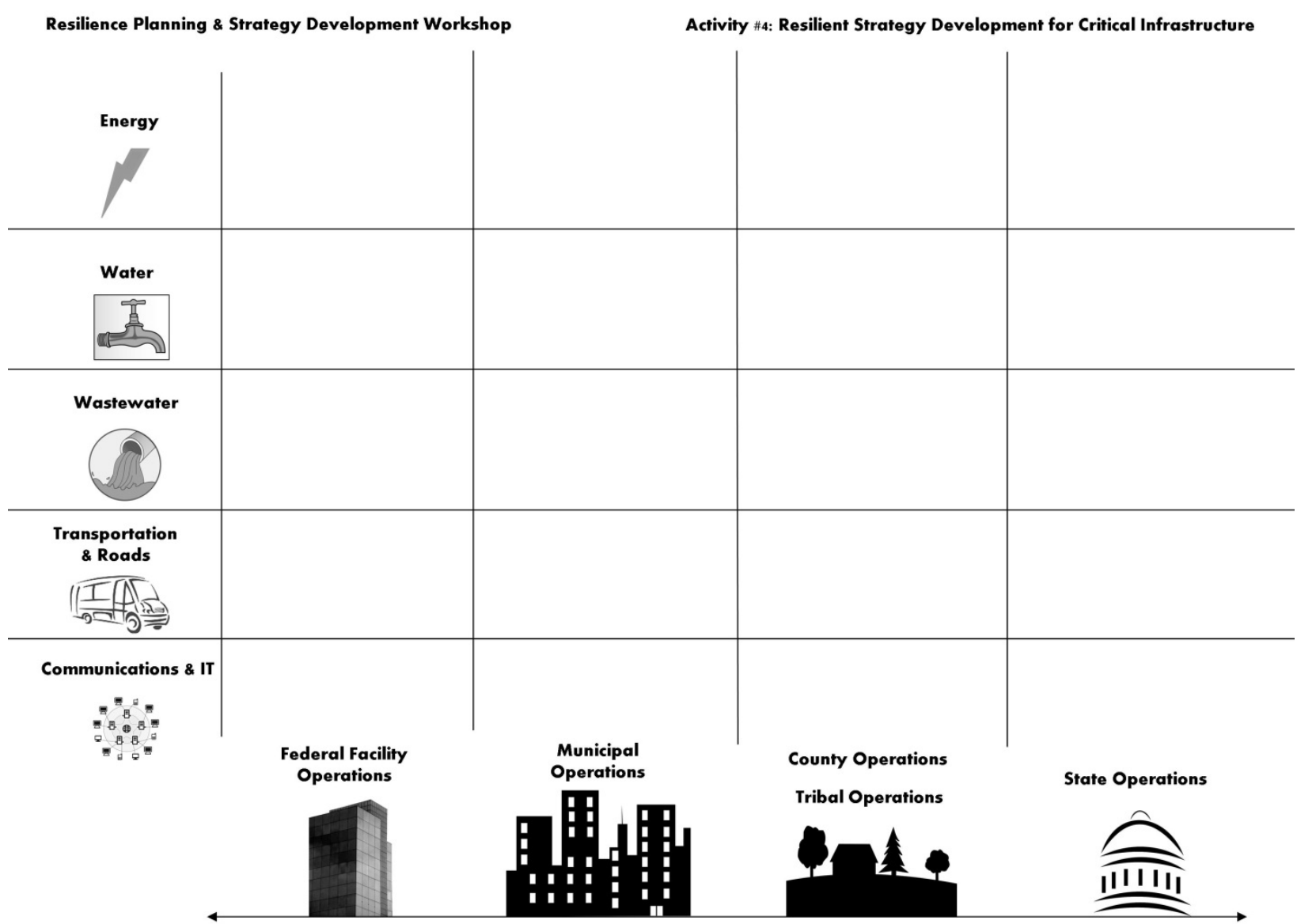

Figure D-4. Activity 4: Sample worksheet for facilitators 


\section{Activity 5: Prioritizing Strategies}

\section{Discussion Questions}

- Are any of the identified strategies easy to implement and low cost?

- Would any of the strategies address multiple threats or vulnerabilities?

- Do the strategies support the resilience-related goals?

- Which strategies reduce the greatest risk the most?

\section{Discussion Tools}

- "Risk-based ranking of actions" in EPA's Being Prepared for Climate Change: A Workbook for Developing Risk-Based Adaptation Plans ${ }^{43}$

- Sector worksheets NIST's Community Resilience Planning Guide for Buildings and Infrastructure Systems ${ }^{44}$

- Facilitators can use the worksheet in Figure D-5 to frame and record the discussion.

\footnotetext{
${ }^{43}$ Page 85 of EPA, Being Prepared for Climate Change: A Workbook for Developing Risk-Based Adaptation Plans (Washington, D.C.: EPA Office of Water, 2014) https://www.epa.gov/sites/production/files/2014-09/documents/being_prepared_workbook_508.pdf.

${ }_{44}^{4}$ NIST, Community Resilience Planning Guide for Buildings and Infrastructure Systems: Volume II, NIST Special Publication 1190. (U.S. Department of Commerce, National Institute of Standards and Technology, 2016). http://www.nist.gov/el/resilience/upload/NIST-SP-1190v2.pdf.
} 


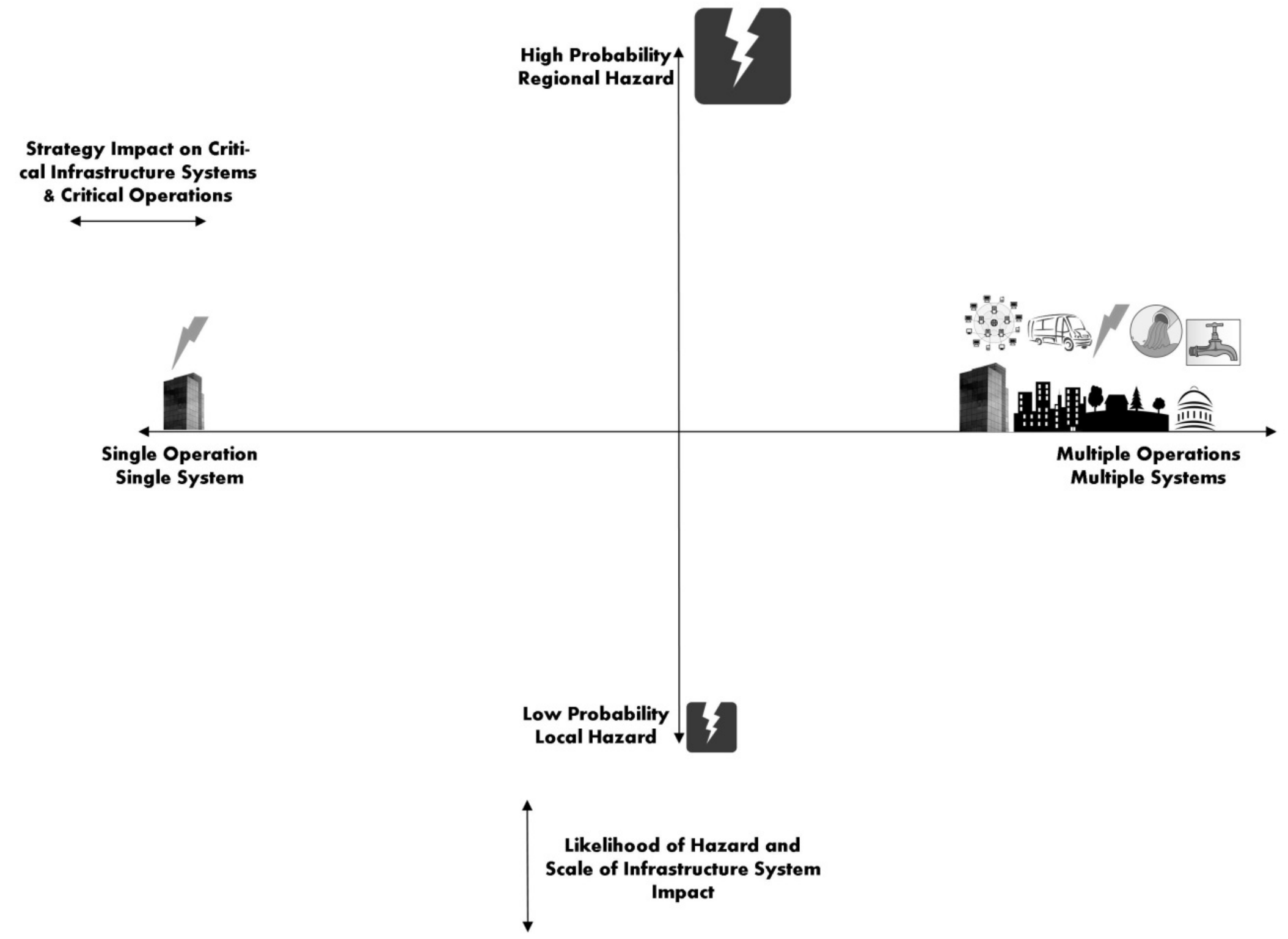

Figure D-5. Activity 5: Sample worksheet for facilitators 